\title{
A robust gap-filling approach for ESA CCI soil moisture by integrating satellite observations, model-driven knowledge and spatiotemporal machine learning
}

\author{
Kai Liu ${ }^{1}$, Xueke Li ${ }^{2}$, Shudong Wang ${ }^{1}$, Hongyan Zhang ${ }^{1}$
}

$5{ }^{1}$ Aerospace Information Research Institute, Chinese Academy of Sciences, Beijing 100094, China.

${ }^{2}$ Institute at Brown for Environment and Society, Brown University, Providence, RI, 02912, USA

Correspondence to: Shudong Wang(wangsd@aricas.ac.cn)

\begin{abstract}
Soil moisture (SM) is a critical component of the water cycle and a key ecological process connecting the soilvegetation-atmosphere system. Spatiotemporally continuous SM is increasingly demanded for ecological and hydrological
\end{abstract} research fields. Satellite remote sensing has opened opportunities for mapping SM. Nevertheless, the continuity of SM imagery is hampered by data gaps resulting from inadequate satellite coverage and radio frequency interference. In light of this, we propose a new gap-filling approach to reconstruct daily SM time series using the European Space Agency’s Climate Change Initiative (ESA CCI). The developed approach integrates satellite observations, model-driven knowledge and machine learning algorithm that leverages both spatial and temporal domains. Taking SM in China as an example, we show

15 high accuracy of the reconstructed SM when validated with multiple sets of in situ measurements, with a root mean square error (RMSE) and mean absolute error (MAE) of 0.09-0.14 and $0.07-0.13 \mathrm{~cm}^{3} / \mathrm{cm}^{3}$, respectively. Further evaluation with a 10 fold cross validation reveals a median value of the coefficient of determination ( $\left.\mathrm{R}^{2}\right)$, RMSE, and MAE of $0.56,0.025$ $\mathrm{cm}^{3} / \mathrm{cm}^{3}$ and $0.019 \mathrm{~cm}^{3} / \mathrm{cm}^{3}$, respectively. The reconstructive performance is noticeably reduced when excluding an explanatory variable while the rest remains unchanged, as well as when removing the spatiotemporal domain strategy and

20 the residual calibration procedure, respectively. Compared to that using satellite-derived diurnal temperature range (DTR), reconstructed SMs using bias-corrected model-derived DTRs exhibit acceptable accuracies and higher spatial coverage. Applying our gap-filling approach to long-term SM data sets (2005-2015), we show a promising result with a $\mathrm{R}^{2}$ of 0.72 . A more accurate trend is achieved relative to that of the original CCI SM when assessed with in situ measurements ( 0.45 versus 0.23 in terms of $\mathrm{R}^{2}$ ). Our findings indicate the feasibility of integrating satellite observations, model-driven knowledge, and 25 spatiotemporal machine learning for filling gaps in SM time series over short and long time scales, providing a potential avenue for applications to similar studies.

\section{Introduction}

As an essential component of land-atmosphere interactions, soil moisture (SM) substantially impacts the energy, water, and carbon cycles. It plays an important role in hydrological, environmental, and agricultural applications such as 
30 evapotranspiration estimation (Detto et al., 2006), drought assessment (Wang et al., 2011), and flood forecasting (Wanders et al., 2014). SM has been declared by the Global Climate Observing System (GCOS) and United Nations Framework Convention on Climate Change (UNFCCC) as one of the 50 vital variables in terrestrial domains. Spatially and temporally continuous daily all-weather SM facilitates understanding of ecological and hydrological processes, and a reliable SM dataset is urgently demanded.

35 There are a variety of ways of collecting SM. In situ measurements can capture the temporal variability of SM at the station scale. Plenty of in-situ monitoring networks have been installed regionally, nationally and globally, e.g., the crop growth and farmland SM database in China, the North American Soil Moisture Database in North America, and the International Soil Moisture Network (ISMN) (Schaake et al., 2004; Dorigo et al., 2011). Nevertheless, owing to the limited ground stations, it is challenging to obtain spatially continuous SM measurements across large-scale regions. In addition to ground-based observations, SM can be simulated with various numerical models. The Global Land Data Assimilation System (GLDAS) and European Centre for Medium-Range Weather Forecasts (ECMWF) fifth-generation global atmospheric reanalysis (ERA5) can model the soil moisture values that have sufficient spatial coverage (Chen et al., 2013; Reichle et al., 2011). However, these model simulated dataset tends to be sensitive to the uncertainties relating to model structure, forcing, and parameterization (Prihodko et al., 2008).

45 Satellite observation has been considered as one powerful technique for retrieving surface SM especially accompanying the increasing improvement of sensor technology (Crow et al., 2012). Some SM-dedicated satellites, e.g., the Advanced Microwave Scanning Radiometer-Earth Observation System (AMSR-E), and Advanced Scatterometer (ASCAT) have used the higher C-band and X-band microwave frequencies to collect SM signals (Paloscia et al., 2001). However, these satellite systems are less subject to atmospheric variability and vegetation coverage. Apart from this, some observation sensors are

50 installed with the lower L-band radiometers, such as the Soil Moisture and Ocean Salinity (SMOS) (Kerr et al., 2001) and Soil Moisture Active and Passive (SMAP) (Entekhabi et al., 2010). These observation systems have exhibited great potential in collecting SM sources due to the strong capacity of L-band in penetrating vegetation. A case worth noting is that the Climate Change Initiative of the European Space Agency (ESA CCI) has generated one set of global SM dataset (Gruber et al., 2019; Dorigo et al., 2017). This CCI SM product blends a series of SM products from active passive microwave satellite

55 sensors, enabling it one complete and consistent observational SM record. Despite some uncertainties, earlier studies have revealed good accordance between the CCI SM and the in situ measurements over different regions (Dorigo et al., 2015).

Although the active and passive microwave satellite sensors can depict soil moisture characteristics across large scales, the gap issues still exist in these satellite-based SM products. This is related to a variety of factors, such as the radio-frequency interference and orbit changes of satellite sensors. Considerable efforts have been dedicated to filling the missing values in

60 the satellite-derived SM dataset. Traditional interpolation approaches are applied to fill gaps relying on the spatial or temporal patterns of the target variable, such as the inverse distance weighting and cokriging (Yao et al., 2013; Ford and Quiring, 2014). Some other studies focus on statistical methods that mainly depend on the statistical and physical relationships between target variables and explanatory variables (Leng et al., 2017). Machine learning strategies have been 
recently introduced in gap-filling the satellite dataset (Zhang et al., 2021c; Zhang et al., 2021b). These methods have a strong capacity in depicting complex relationships of target variables and explanatory variables. Compared to statistical-based models, the machine learning models may be more flexible and robust especially regarding the complex scenes and extended coverage (Reichstein et al., 2019).

Most current SM gap-filling studies typically rely on explanatory variables that are required in describing SM dynamics. The common explanatory variables include satellite-derived vegetation index (e.g., normalized difference vegetation index (NDVI) and enhanced vegetation index (EVI)), surface albedo and land surface temperature (LST), as well a variety of climatic and geographical factors have been employed in these studies (Almendra-Martín et al., 2021; Cui et al., 2019; Jing et al., 2018). Nevertheless, most of these variables are less suitable in heterogeneous regions and extended coverage, although they are suitable for regional areas. For example, previous studies (Song et al., 2021; Liu et al., 2020b) illustrated that studies focusing on NDVI and LST tend to achieve better performance in delineating SM in arid and semi-arid regions, but produce unsatisfactory performance in humid areas. Moreover, these satellite-derived variables (e.g., optical and thermal infrared parameters) are likely to be impacted by cloud conditions. Accordingly, researchers have attempted to explore effective information for promoting model establishment and application. Some studies use the feature transform approaches to extract distinct signals for driving models. Principal component analysis (PCA) and wavelet decomposition have been employed to reconstruct SM and other satellite-based parameters (Uebbing et al., 2017; Almendra-Martín et al., 2021).

80 Despite pretty good model performance achieved in the humid and semi-arid region (Zhang et al., 2016; Almendra-Martín et al., 2021), some studies found that there is no substantial improvement in model performance in cropland of semi-humid region when using the PCA (Wang et al., 2020). Some other studies have focused on the distinct dataset source for gapfilling models. Soil moisture from GLDAS, ERA5, China Meteorological Administration Land Data Assimilation System (CLDAS) and Fengyun Microwave Radiation Imager is considered (Long et al., 2019; Cui et al., 2020). The gap-filling models integrating these unique dataset sources are able to describe SM dynamics, but uncertainties are still observed in the humid regions and freezing-thaw areas (Song et al., 2021; Cui et al., 2019). Overall, the availability of explanatory variables in contributing SM reconstructing models is inadequately explored, which is especially critical for machine learning gapfilling models that are sensitive to the structure of input sequences (Mao et al., 2019).

Although earlier studies have focused on completing the SM dataset, most of them partially aim at the specific case of

90 satellite observations but less consider the large continental region. Almendra-Martín et al. (2021) and Liu et al. (2020b) applied reconstruction algorithms to the CCI SM product in regional Europe and Oklahoma, USA, respectively, and Cui et al. (2019) continuously promote this approach in the Tibetan Plateau. These models rely on machine learning algorithms and a variety of satellite-based variables. Furthermore, studies aimed at the challenging case of time series SM dataset at the daily scale are insufficiently implemented (Zhang et al., 2021c; Long et al., 2019), which is fundamental to explore the SM

95 dynamics and quantify its impacts and contribution on climate change and water cycle.

This study proposes a robust gap-filling methodology for reconstructing a spatially continuous daily ESA CCI SM, primarily based on satellite observations, model-driven knowledge and one spatiotemporal random forest algorithm. Our model is 
https://doi.org/10.5194/hess-2022-76

applied to continental China which has sufficient landscape variability and climatic conditions. To be specific, the feasibility and merit of the developed model are demonstrated by 1) evaluating the gap-filled results with the in-situ measurements and the holdout cross-validation, and comparing against those of other models; and 2) discussing the model uncertainty in terms of the filtered explanatory variables, and extending the proposed model to one long-term period.

\section{Study region and material}

\subsection{Study region}

China is located from $3^{\circ} 51^{\prime} \mathrm{N}$ to $53^{\circ} 33^{\prime} \mathrm{N}$ and from $73^{\circ} 33^{\prime} \mathrm{E}$ to $135^{\circ} 05^{\prime} \mathrm{E}$, covering an area of approximately $9.6 \times 10^{6} \mathrm{~km}^{6}$

(Fig. 1). A variety of terrain types are presented across China, including the plain, basin, plateau, mountain and hill. These diverse terrains inevitably result in noticeable spatial differences in precipitation and temperature, accompanying the elevation decreasing from west to east. Seven climate zones can be identified in China, including arid, semi-arid, arid/semiwet, wet/semi-arid, wet, moist, and over-wet climates. The identification of this zoning system is based on a China's humidity index map produced by the National Earth System Science Data Center, National Science \& Technology

110 Infrastructure of China (http://www.geodata.cn).

In addition to the whole regions of China, we also chose two local regions for model uncertainty analysis (Fig. 1). One region is focused on northern China (NC) which is mostly occupied by arid and semi-arid areas, while the other region is focused on southern China (SC) that is occupied by wet areas.

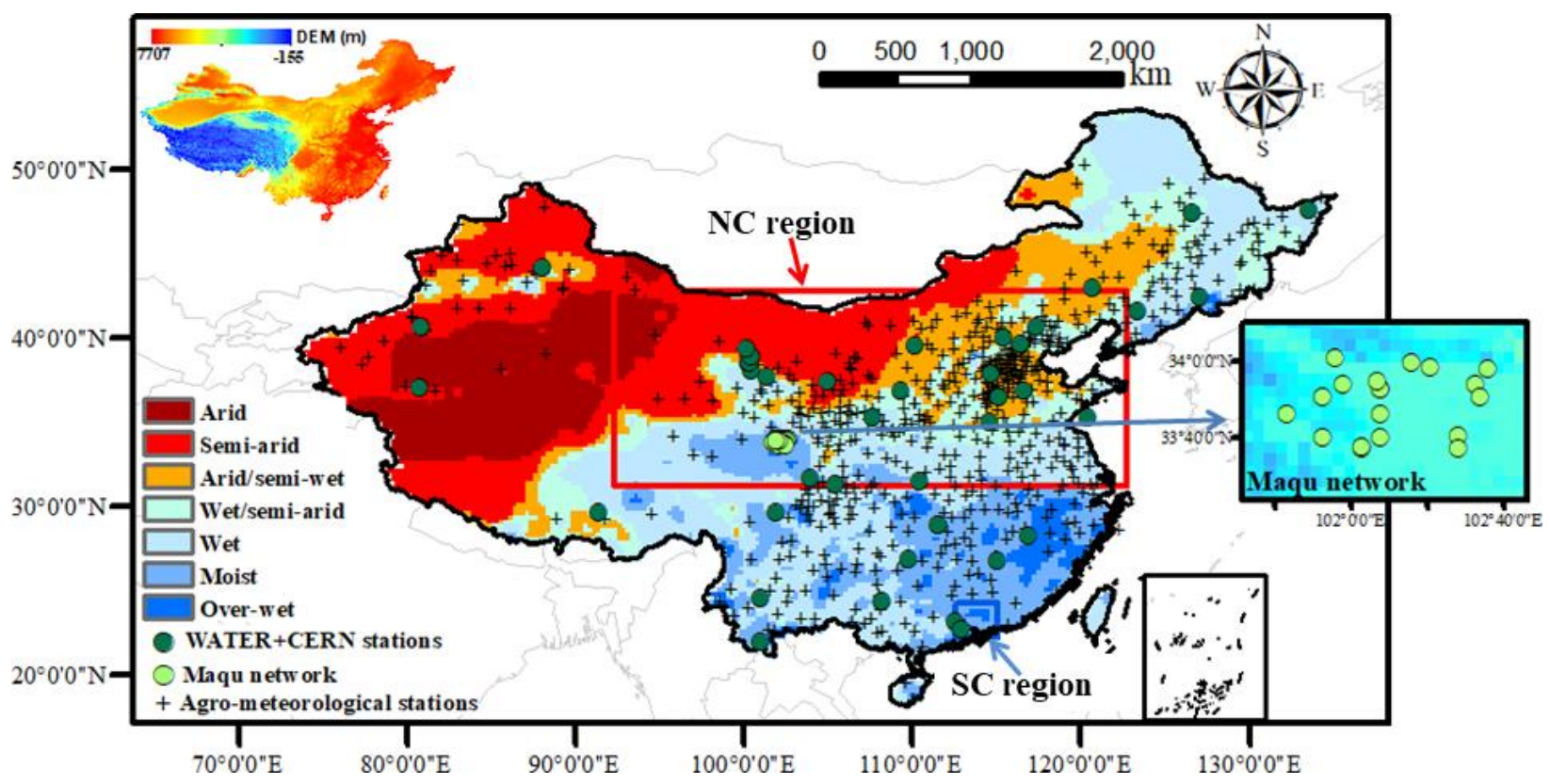


115 Figure 1: The study region and the selected in situ soil moisture sites. The figure in the upper-left corner delineates the DEM information. The detailed distribution of dense in situ measurements in the Maqu network is shown in the figure on the far right. Two regional areas for uncertainty analysis (i.e., northern China (NC) and southern China (SC)) are delineated with the rectangle.

\subsection{Material}

The dataset used mainly includes, i) satellite product, reanalysis dataset, and land surface model products for the model establishment, ii) in situ measurements for model validation, and iii) reanalysis dataset and land surface model dataset for model performance analysis. Table 1 (and Table S1) provides the information of the used dataset. Details about these datasets are described in the following sections.

Table 1. Summary of the dataset used for the proposed model. Other dataset for the preliminary analysis but not the final utilization of the model is exhibited in supplementary Table $\mathbf{S 1}$.

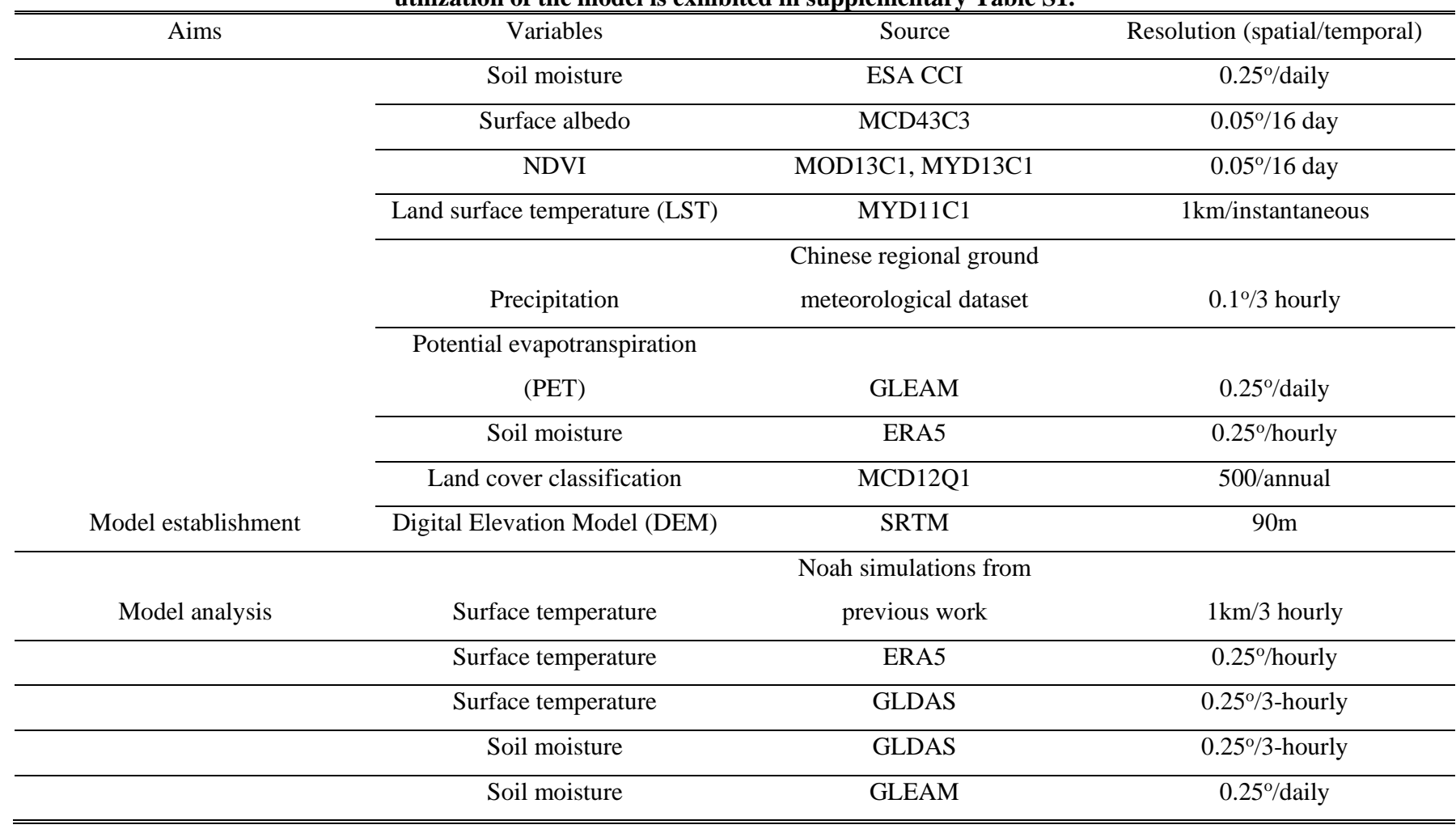

\subsubsection{Satellite dataset}

The ESA CCI SM dataset is provided by the Climate Change Initiative program of the European Space Agency. This product is primarily composed of three types of daily dataset sources, i.e., active, passive, and active-passive combined microwave products (Dorigo et al., 2017). Despite the wide spatiotemporal coverage of CCI SM, the data gap remains a major challenge that hampers its further application. Here we select the daily combined microwave products version 4.5 ,

130 with a spatial resolution of $0.25^{\circ}$. The inconsistent data in the CCI combined SM is filtered using the quality flag variable. 
A variety of Moderate Resolution Imaging Spectroradiometer (MODIS) products are collected, including the $0.05^{\circ}$ daily LST (MYD11C1), the $0.05^{\circ} 16$-day composite albedo (MCD43C3), the $0.05^{\circ} 16$-day composite vegetation indices, i.e., normalized difference vegetation index (NDVI) and enhanced vegetation index (EVI), and the 8-day composite 500-meter leaf area index (LAI) (MCD15A2H). All these datasets are collected at MODIS 6 collection. We calculate the diurnal temperature range (DTR) by subtracting the night LST from daytime LST. The NDVI and EVI are averagely obtained from the two products: MOD13C1 and MYD13C1. All the selected products are screened out using the quality variables to maintain only the available pixels with good quality. We also collect the $0.05^{\circ}$ annual land cover product (MCD12Q1) for quality control of CCI SM.

Topography may be related to the spatial distribution of soil moisture. We use the Digital Elevation Model (DEM) dataset provided by NASA's Shuttle Radar Topography Mission (SRTM) to retrieve several relevant topographic metrics. SRTM dataset has been extensively employed (Van Zyl, 2001), and it has an original spatial resolution of $90 \mathrm{~m}$. The slope, aspect, and the topographic position index (TPI) (Guisan et al., 1999) are used. The TPI is calculated by subtracting the focal grid elevation with and the mean elevation of the eight surrounding grids.

Considering the low accuracy of satellite SM for snow-covered pixels, the pixel that has both daytime LST lower than $0{ }^{\circ} \mathrm{C}$

145 and the albedo higher than 0.3 are removed (Cui et al., 2020). We also remove the pixel that occupies more than $20 \%$ of the water body. To overcome the spatial resolution differences among the diverse available products, all datasets are resampled to $0.25^{\circ}$ spatial resolution by averaging the pixel values.

\subsubsection{Reanalysis dataset and land surface model dataset}

We collect the soil moisture data from ERA5, one global atmospheric reanalysis dataset released by the ECMWF (Balsamo

150 et al., 2015). The data assimilation system used for ERA5 is the ECMWF Integrated Forecast System (IFS), and the meteorological forcing for retrieving soil moisture is from the ERA atmospheric reanalysis. It can provide soils at four soil depths $(0-7,7-28,28-100$, and 100-289 cm). Here we select the daily averaged SM from the first soil layer to match with satellite CCI SM.

Daily potential evapotranspiration (PET) and surface soil moisture $(0-15 \mathrm{~cm})$ is collected from the Global Land-surface

155 Evaporation Amsterdam Methodology (GLEAM) dataset. GLEAM is based on a general land surface model that focuses on soil moisture and evapotranspiration (Miralles et al., 2011). PET in the GLEAM is calculated with the Priestley-Taylor formula based on multiple reanalysis datasets.

The soil moisture is calculated with a soil-water module based on water cycle balance.

Four meteorology variables are obtained from the Chinese regional ground meteorological dataset. They are precipitation, air temperature, solar radiation, and wind. This dataset has a temporal resolution of 3-hourly and a spatial resolution of $0.1^{\circ}$. Considering the lag effect of precipitation on surface water dynamics, we use the five-day antecedent precipitation (AP) to replace the daily precipitation (Wei et al., 2020). Specifically, AP is estimated as follows: 
$\mathrm{AP}=\frac{\sum_{i=1-m}^{i=0} P_{i}}{m}$,

where $P_{i}$ is the precipitation at the day $i ; m$ is the number of prior days for AP owing the highest absolute correlation between SM and precipitation. Here we set $m$ as five based on the regional hydrological and climatic variability.

Three surface temperature sources are additionally collected for uncertainty analysis. Two sources are collected from the ERA5 and GLDAS ensemble model. Considering the model uncertainties caused by regional surface characteristics and climatic conditions, we simulate surface temperature and surface soil moisture $(0-10 \mathrm{~cm})$ by implementing one Noah model that is forced with meteorology variables from the Chinese regional ground meteorological dataset and the surface condition parameters from MODSI. This dataset is previously used in our work (Liu et al., 2020a; Liu et al., 2021b). All these surface temperatures and soil moisture are resampled to a $0.25^{\circ}$ grid.

\subsubsection{In situ measurements}

A variety of spatially sparse in situ soil moisture measurements is collected to evaluate the accuracy of gap-filled SM. We collect in situ soil moisture observations at 39 sites obtained from the China Watershed Allied Telemetry Experimental

175 Research (WATER) project and the Chinese Ecosystem Research Network (CERN). These validation stations are set up in a relatively large homogeneous area dominated by vegetation covers (cropland, woodland and grassland) or desert lands. In addition, 657 in situ soil moisture measurements are collected from the Chinese agro-meteorological and ecological observation network. These stations are covered by cropland. All these selected in situ soil moisture measurements have been previously used for validating the satellite-derived soil moisture in China, and their locations and information are displayed in Fig. 1 and Table 2.

We also collect the dense in situ measurements at the Maqu soil moisture monitoring network. The Maqu network $\left(33^{\circ} 30^{\prime}-\right.$ $34^{\circ} 15^{\prime} \mathrm{N}, 101^{\circ} 38^{\prime}-102^{\circ} 45^{\prime} \mathrm{E}$ ) is located on the north-eastern border of the Tibetan Plateau (Fig. 1) (Dente et al., 2012). In this network, 20 sites are distributed over a uniform grassland cover, located in the large valley of the Yellow River. Maqu network has demonstrated strong capability in monitoring the spatial and temporal SM variability with high accuracy. The

185 detailed information of available sites is summarized in Table 2.

Table 2 Summary of the characteristics of in situ sites

\begin{tabular}{c|c|c|c|c|c|c|c|}
\hline \hline ID & Site & Land-use & Elevation & Longitude & Latitude & $\begin{array}{c}\text { Soil } \\
\text { depth }\end{array}$ & $\begin{array}{c}\text { Projections } \\
\text { and references }\end{array}$ \\
\hline 1 & Yucheng & Cropland & $23 \mathrm{~m}$ & $116.57 \mathrm{E}$ & $36.83 \mathrm{~N}$ & $10 \mathrm{~cm}$ & China Watershed Allied \\
2 & Daxing & Cropland & $20 \mathrm{~m}$ & $116.42 \mathrm{E}$ & $39.62 \mathrm{~N}$ & $5 \mathrm{~cm}$ & Telemetry Experimental \\
3 & Miyun & Woodland & $350 \mathrm{~m}$ & $117.32 \mathrm{E}$ & $40.63 \mathrm{~N}$ & $5 \mathrm{~cm}$ & Research (WATER), \\
4 & Guantao & Cropland & $30 \mathrm{~m}$ & $115.12 \mathrm{E}$ & $36.51 \mathrm{~N}$ & $2 \mathrm{~cm}$ & (Zhang et al., 2021a) \\
5 & Arou & Grassland & $2995 \mathrm{~m}$ & $100.46 \mathrm{E}$ & $38.04 \mathrm{~N}$ & $10 \mathrm{~cm}$ & (Li et al., 2009) \\
6 & Maliantan & Grassland & $2817 \mathrm{~m}$ & $100.30 \mathrm{E}$ & $38.55 \mathrm{~N}$ & $5 \mathrm{~cm}$ & (Huang et al., 2016) \\
& & & & & & &
\end{tabular}


https://doi.org/10.5194/hess-2022-76

Preprint. Discussion started: 4 March 2022

(c) Author(s) 2022. CC BY 4.0 License.

\begin{tabular}{|c|c|c|c|c|c|c|c|}
\hline $\begin{array}{l}7 \\
8\end{array}$ & $\begin{array}{l}\text { Yingke } \\
\text { Guantan }\end{array}$ & $\begin{array}{l}\text { Cropland } \\
\text { Woodland }\end{array}$ & $\begin{array}{l}1519 \mathrm{~m} \\
2835 \mathrm{~m}\end{array}$ & $\begin{array}{l}100.42 \mathrm{E} \\
100.25 \mathrm{E}\end{array}$ & $\begin{array}{l}38.85 \mathrm{~N} \\
38.53 \mathrm{~N}\end{array}$ & $\begin{array}{l}5 \mathrm{~cm} \\
5 \mathrm{~cm}\end{array}$ & \\
\hline 9 & AKA & cropland & $1008 \mathrm{~m}$ & $80.85 \mathrm{E}$ & $40.67 \mathrm{~N}$ & $10 \mathrm{~cm}$ & Chinese Ecosystem \\
\hline 10 & $\mathrm{ALF}$ & Woodland & $2455 \mathrm{~m}$ & $101.02 \mathrm{E}$ & $24.54 \mathrm{~N}$ & $5 \mathrm{~cm}$ & Research Network \\
\hline 11 & ASA & cropland & $1296 \mathrm{~m}$ & $109.31 \mathrm{E}$ & $36.85 \mathrm{~N}$ & $10 \mathrm{~cm}$ & $(\mathrm{CERN})$ \\
\hline 12 & $\mathrm{BJF}$ & Woodland & $1162 \mathrm{~m}$ & $115.43 \mathrm{E}$ & $39.97 \mathrm{~N}$ & $5 \mathrm{~cm}$ & (Yu et al., 2006) \\
\hline 13 & $\mathrm{BNF}$ & Woodland & $722 \mathrm{~m}$ & $101.02 \mathrm{E}$ & $21.95 \mathrm{~N}$ & $10 \mathrm{~cm}$ & (Li et al., 2018a) \\
\hline 14 & $\mathrm{CBF}$ & Woodland & $512 \mathrm{~m}$ & $127.09 \mathrm{E}$ & $42.40 \mathrm{~N}$ & $5 \mathrm{~cm}$ & (Zhu et al., 2007) \\
\hline 15 & CLD & Desert & $1342 \mathrm{~m}$ & $80.70 \mathrm{E}$ & $37.01 \mathrm{~N}$ & $10 \mathrm{~cm}$ & (Yao et al., 2018) \\
\hline 16 & CSA & cropland & $21 \mathrm{~m}$ & $120.38 \mathrm{E}$ & $35.25 \mathrm{~N}$ & $10 \mathrm{~cm}$ & \\
\hline 17 & CWA & cropland & $1241 \mathrm{~m}$ & $107.67 \mathrm{E}$ & $35.25 \mathrm{~N}$ & $10 \mathrm{~cm}$ & \\
\hline 18 & DHF & Woodland & $412 \mathrm{~m}$ & $112.53 \mathrm{E}$ & $23.17 \mathrm{~N}$ & $15 \mathrm{~cm}$ & \\
\hline 19 & ESD & Desert & $1301 \mathrm{~m}$ & $110.18 \mathrm{E}$ & $39.50 \mathrm{~N}$ & $10 \mathrm{~cm}$ & \\
\hline 20 & FKD & Desert & $578 \mathrm{~m}$ & $88.00 \mathrm{E}$ & $44.15 \mathrm{~N}$ & $10 \mathrm{~cm}$ & \\
\hline 21 & FQA & cropland & $65 \mathrm{~m}$ & $114.55 \mathrm{E}$ & $35.02 \mathrm{~N}$ & $10 \mathrm{~cm}$ & \\
\hline 22 & GGF & Woodland & $6967 \mathrm{~m}$ & $101.88 \mathrm{E}$ & $29.60 \mathrm{~N}$ & $10 \mathrm{~cm}$ & \\
\hline 23 & $\mathrm{HBG}$ & Grassland & $3321 \mathrm{~m}$ & $101.33 \mathrm{E}$ & $37.66 \mathrm{~N}$ & $5 \mathrm{~cm}$ & \\
\hline 24 & HJA & cropland & $305 \mathrm{~m}$ & $108.20 \mathrm{E}$ & $24.40 \mathrm{~N}$ & $10 \mathrm{~cm}$ & \\
\hline 25 & HLA & cropland & $221 \mathrm{~m}$ & $126.63 \mathrm{E}$ & $47.43 \mathrm{~N}$ & $10 \mathrm{~cm}$ & \\
\hline 26 & HSF & Woodland & $102 \mathrm{~m}$ & $112.90 \mathrm{E}$ & $22.70 \mathrm{~N}$ & $10 \mathrm{~cm}$ & \\
\hline 27 & HTF & Woodland & $294 m$ & $109.75 \mathrm{E}$ & $26.83 \mathrm{~N}$ & $10 \mathrm{~cm}$ & \\
\hline 28 & LCA & cropland & $52 \mathrm{~m}$ & $114.68 \mathrm{E}$ & $37.88 \mathrm{~N}$ & $10 \mathrm{~cm}$ & \\
\hline 29 & LSA & cropland & $4230 \mathrm{~m}$ & $91.33 \mathrm{E}$ & $29.66 \mathrm{~N}$ & $5 \mathrm{~cm}$ & \\
\hline 30 & LZD & cropland & $1363 \mathrm{~m}$ & $100.12 \mathrm{E}$ & $39.33 \mathrm{~N}$ & $10 \mathrm{~cm}$ & \\
\hline 31 & MXF & Woodland & $2035 \mathrm{~m}$ & $103.90 \mathrm{E}$ & $31.70 \mathrm{~N}$ & $10 \mathrm{~cm}$ & \\
\hline 32 & NMD & Desert & $348 \mathrm{~m}$ & $120.70 \mathrm{E}$ & $42.92 \mathrm{~N}$ & $10 \mathrm{~cm}$ & \\
\hline 33 & QYA & cropland & $48 \mathrm{~m}$ & $115.07 \mathrm{E}$ & $26.74 \mathrm{~N}$ & $10 \mathrm{~cm}$ & \\
\hline 34 & SNF & Woodland & $1611 \mathrm{~m}$ & $110.40 \mathrm{E}$ & $31.50 \mathrm{~N}$ & $10 \mathrm{~cm}$ & \\
\hline 35 & SPD & cropland & $1413 \mathrm{~m}$ & $104.95 \mathrm{E}$ & $37.45 \mathrm{~N}$ & $10 \mathrm{~cm}$ & \\
\hline 36 & SYA & cropland & $35 \mathrm{~m}$ & $123.40 \mathrm{E}$ & $41.52 \mathrm{~N}$ & $10 \mathrm{~cm}$ & \\
\hline 37 & TYA & cropland & $62 \mathrm{~m}$ & $111.50 \mathrm{E}$ & $28.91 \mathrm{~N}$ & $10 \mathrm{~cm}$ & \\
\hline 38 & YGA & cropland & $448 \mathrm{~m}$ & $105.45 \mathrm{E}$ & $31.27 \mathrm{~N}$ & $10 \mathrm{~cm}$ & \\
\hline 39 & YTA & cropland & $44 \mathrm{~m}$ & $116.92 \mathrm{E}$ & $28.25 \mathrm{~N}$ & $10 \mathrm{~cm}$ & \\
\hline $40-59$ & Maqu network & Grassland & $\sim 3430 \mathrm{~m}$ & $\begin{array}{l}101.63- \\
102.75 \mathrm{E}\end{array}$ & $\begin{array}{c}33.5- \\
34.25 \mathrm{~N}\end{array}$ & $5 \mathrm{~cm}$ & $\begin{array}{c}\text { Tibetan Plateau } \\
\text { observatory of plateau } \\
\text { scale soil moisture }\end{array}$ \\
\hline
\end{tabular}




\begin{tabular}{|c|c|c|c|c|c|c|c|}
\hline & & & & & & & $\begin{array}{c}\text { and soil temperature } \\
\text { (Tibet-Obs), } \\
\text { (Su et al., 2013) } \\
\text { (Wei et al., 2019) }\end{array}$ \\
\hline $60-716$ & $\begin{array}{c}\text { Agro- } \\
\text { meteoroloical } \\
\text { stations }\end{array}$ & Cropland & $\begin{array}{c}-84- \\
4200 \mathrm{~m}\end{array}$ & $\begin{array}{c}75.98- \\
134.28 \mathrm{E}\end{array}$ & $\begin{array}{c}18.5- \\
51.72 \mathrm{~N}\end{array}$ & $10 \mathrm{~cm}$ & $\begin{array}{c}\text { China's } \\
\text { agrometeorological } \\
\text { observation network, } \\
\text { (Meng et al., 2021) } \\
\text { (Wang et al., 2016) }\end{array}$ \\
\hline
\end{tabular}

\section{Methods}

Our study aims to reconstruct the CCI SM data gaps for obtaining spatially continuous records. The basic idea beneath the proposed gap-filling approach is to efficiently depict the correlation between the SM records and the corresponding explanatory variables, which can be expressed as:

$S M=f\left(V_{1}, V_{2}, V_{3} \cdots \cdots V_{k}\right)+\varepsilon$,

$V_{i} \in R^{N, T}$,

where $S M$ is the soil moisture, $\mathrm{V}_{\mathrm{i}}$ is the corresponding explanatory vectors, and $k$ is the number of the input variables. $\mathrm{V}_{\mathrm{i}}$ can be a vector the sample number of which is decided by the spatial domain $(N)$ and temporal domain $(T)$. $\mathrm{f}$ is one function that can be either linear or nonlinear. $\varepsilon$ represents the model residual. In machine learning ensemble, $f$ represents a black box model that does not have one specific form.

Proposed methodology mainly involves the following steps: (i) using a regression subset selection model and a variable correction procedure to filter explanatory variables from the satellite observations and model-driven knowledge, and removing the systematic bias between them; (ii) applying a random forest algorithm to delineate the SM-explanatory variables correlation based on the available pixels identified with a spatiotemporal window search strategy, and then employing the established correlation to retrieve the unavailable SM pixels; and (iii) conducting a geographically weighted regression and Gaussian filtering to calibrate the model-derived residuals. Figure 2 shows the overall diagram of our work. 


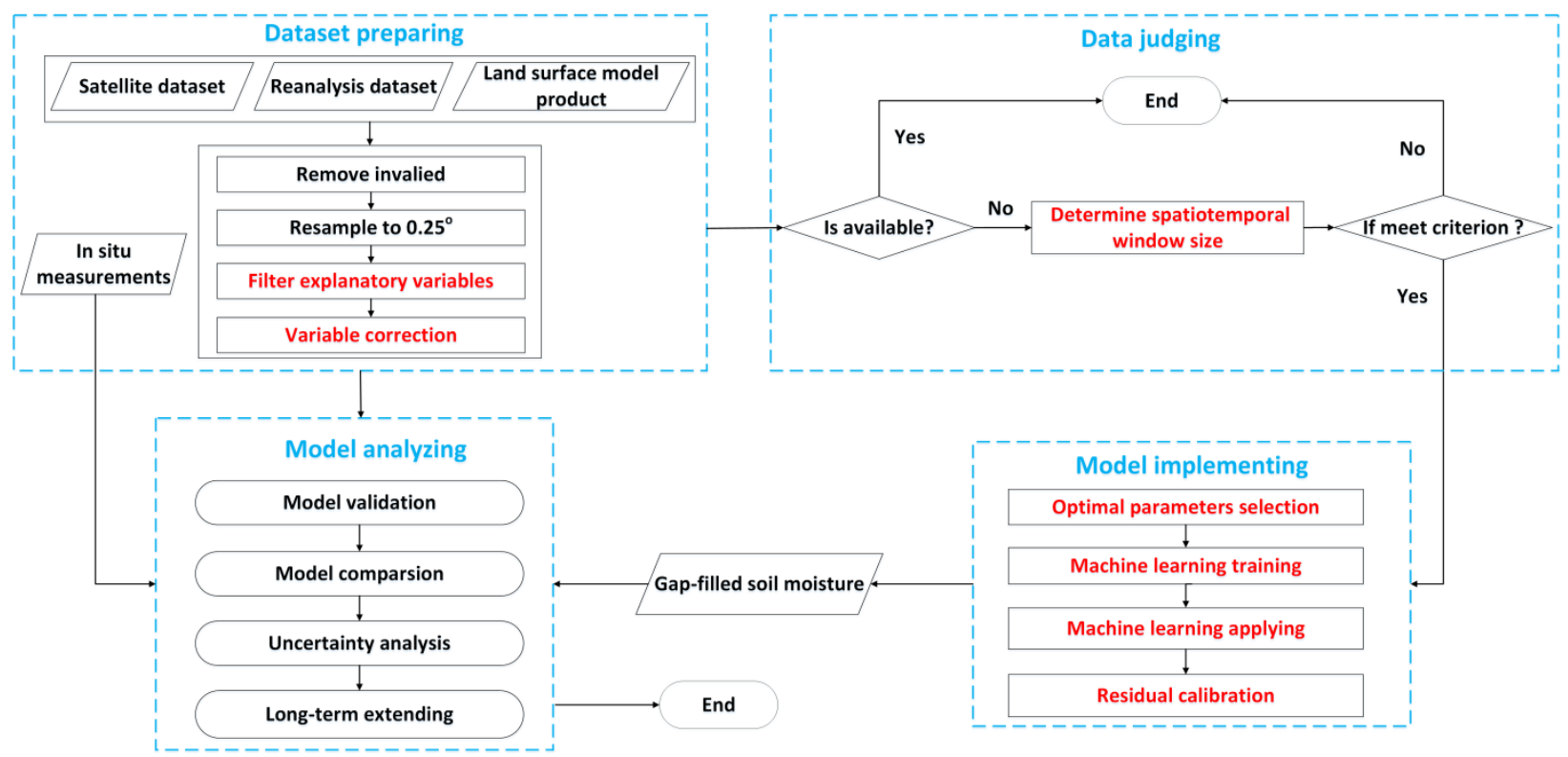

Figure 2: The overall diagram of the proposed methodology. The main work carried out includes dataset preparing, data judging, model implementing, and model analyzing.

\subsection{Explanatory variables filtering}

\subsection{Explanatory variables}

Explanatory variables related to atmospheric, geophysical, ecological and hydrological variables are conductive in capturing SM variability. The main assumption beneath this approach is that the suppressor variables are associated significantly with each other in regression models, although they may be less correlated with the dependent variables. The significance percentage produced in the regression subset selection model (Fu et al., 2019; Liu et al., 2021a) is employed to measure the impacting probability of explanatory variables, and the high significance percentage indicates the strong ability to depict SM. To be specific, we successively (1) use a least-squares linear regression to check the potential relationships between SM and explanatory variables; (2) apply a stepwise regression to explore plenty of potential explanatory variables based on the

215 Akaike Information Criterion (AIC); (3) exploit the best models from all variable combination to identify the important variables impacting SM; and (4) quantify the relative contributions of each explanatory variable to SM based on importance criterion.

We conduct the subset selection model analysis based on the dataset during 2005-2015. 15 variables are selected as input parameters, including seven surface environmental variables, i.e., Albedo, NDVI, EVI, LAI, DTR, PET and ERA SM, three elevation variables, i.e., TPI, aspect and slope, three climatic variables, i.e., AP, air temperature, wind, and two geographical factors, i.e., latitude and longitude. Notice that all these variables can be available from a reliable dataset at the continental 
scale. Moreover, these variables have been reported previously (Cui et al., 2016; Liu et al., 2020b; Almendra-Martín et al., 2021) in robustly describing soil moisture.

As illustrated in Fig. 3(a), Albedo, NDVI, EVI, LAI, DTR, AP, PET, ERA SM, TPI and air temperature have the highest significant percentage in correlating to CCI SM. Considering EVI and LAI have closely correlated to NDVI, and air temperature has closely correlated to DTR. EVI, LAI and air temperature are excluded for model application. All these selected covariates are physically meaningful in depicting SM. Atmospheric variables (i.e., precipitation, DTR and PET) are suitable to capture the temporal dynamics of SM. Topographic variables are included to both depict the orographic effects and recapture the spatial pattern of SM. NDVI and Albedo (and DTR) are included owing to their impact on the formation of SM. Specifically, DTR exhibits a substantial correlation with SM owing to its capacity in taking account for landatmosphere coupling. ERA surface moisture is also included to reproduce satellite SM. Despite uncertainties in the numerical model SM simulations, ERA SM provides the fewest dataset gaps. We further investigate the contribution of these variables to SM. As shown in Fig. 3(b) (and Fig. S1), the correlations between the CCI SM and the selected variables are relatively high across the whole of China. This indicates the feasibility of the selected variables in modeling SM. In addition, since these variables are derived from optical remote sensing, reanalysis dataset and land surface model products, they have the potential to extend to large regions due to high availability (Fig. 3(c)).

\subsubsection{Variable correction}

To make the modeled values (i.e., ERA SM) comparable to satellite observations (i.e., ESA CCI SM), it is necessary to remove the systematic bias between them. Here we use one correction procedure (Long et al., 2020; Zhang et al., 2021d), which primarily combines the variance scaling algorithm and the linear scaling algorithm. The used procedure can be illustrated with the following equations:

$\left\{\begin{array}{c}S M_{c 1}=S M_{E R A}\left(t_{a v}\right)-\mu\left(S M_{E R A}\left(t_{a v}\right)\right)+\mu\left(S M_{E S A}\left(t_{a v}\right)\right) \\ S M_{c}=\mu\left(S M_{c 1}\right)+\left(S M_{c 1}-\mu\left(S M_{c 1}\right)\right) \cdot \sigma\left(S M_{E S A}\left(t_{a v}\right)\right) / \sigma\left(S M_{c 1}-\mu\left(S M_{p 1}\right)\right)\end{array}\right.$

where $S M_{E R A}$ is the raw ERA SM time series of the target grid pixel; $t_{a v}$ is time series in which pixels in the object grid are available; $S M_{E S A}$ is the SM of the grid; $\mu$ and $\sigma$ are the mean value and the standard deviation, respectively. $S M_{c}$ is the corrected ERA SM that is assumed to have a spatial pattern (i.e., consistent means and standard deviations) with the CCI SM. In our study, a dataset regarding the time series of 2005-2015 is used to conduct the correction procedure for guaranteeing enough samples. The examples illustrating the performance of ERA SM correction can be found in Fig. S2. Despite being conducted on SM parameters here, this calibration method can be implemented to other parameters (e.g., DTR) when replaced with numerical model outputs. 

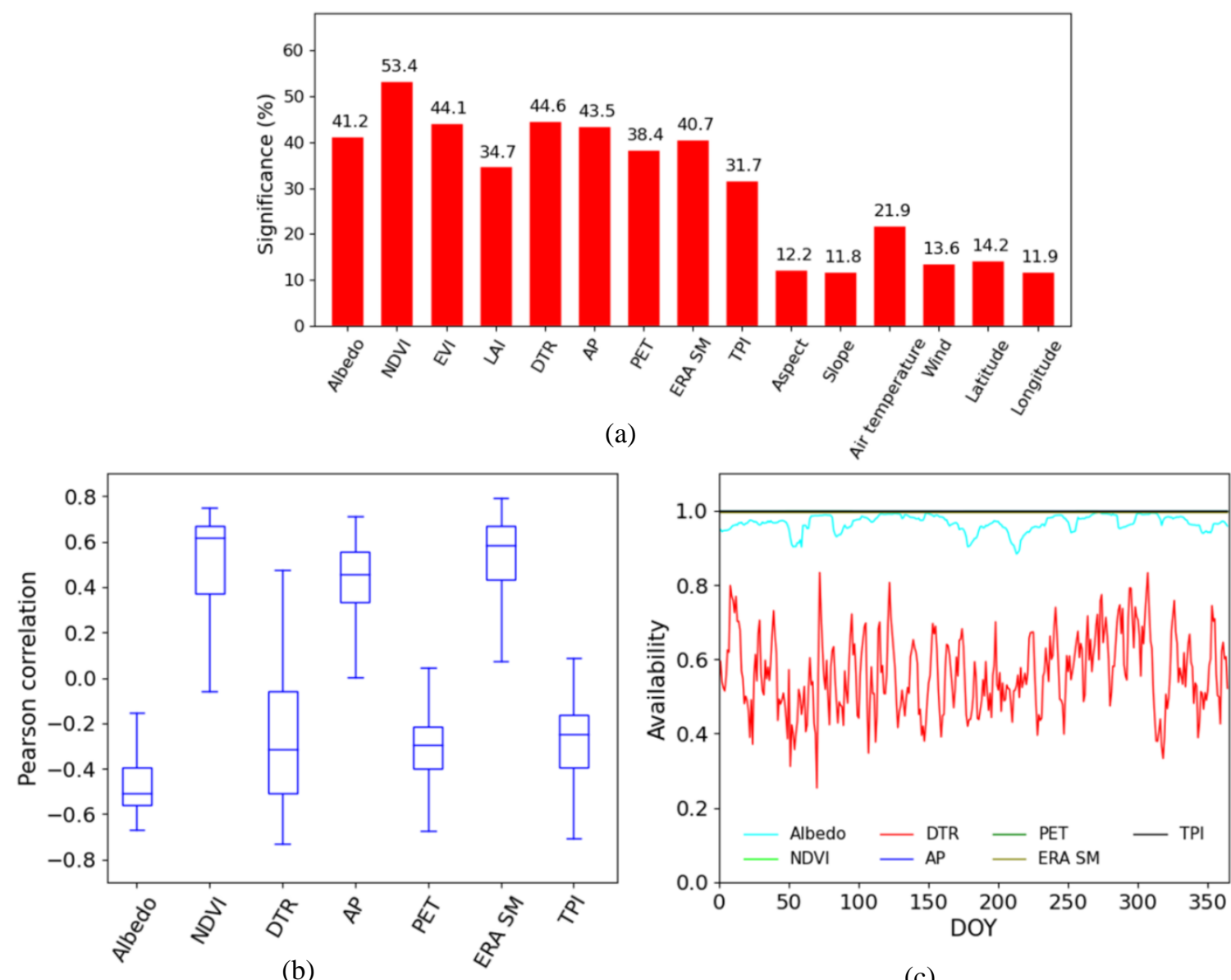

(b)

(c)

Figure 3: The correlation and availability of dataset used. (a) The significance percentage of the selected variables in correlation to CCI SM. (b) The Pearson correlation between the selected variables and CCI SM. (c) The availability of the selected variables.

\subsection{Random Forest regression}

Despite being easy to implement and requiring less computational resources, the traditional regression-based methods cannot provide full probability density functions for evaluating system performance. Ensemble learning approaches may overcome this issue by aggregating results from multiple models. Machine learning approaches could achieve better performance owing to their capacity in reducing overfitting chances and quantifying the accompanying uncertainty. Among the machine learning models, random forest is one effective and powerful tool in interpreting earth variables, acting as an enhanced decision tree model (Belgiu and Drăguț, 2016). As illustrated in Fig. 4, RF is a hierarchical tree diagram, which is based on a nonparametric strategy and therefore is feasible to add layer categories. This decision tree model is composed of many nodes and edges within each tree structure, mainly including two types of nodes: split nodes and leaf nodes. The split node is related to a test function that is employed to split the input data, whereas the leaf node is associated with the final decision. Unlike the standard decision tree model that relied on the whole data set, RF trains each tree on bootstrap resamples. This 
model only considers the randomly selected variables rather than the total variables. By this means, the outcome is decided by one majority voting or averaging strategy.

In this study, the RF model is implemented using the function 'RF Regressor' from the Python Library (Shahriari et al., 2016). Specifically, the built-in functions are used to assess the importance of each covariate by using the out-of-bag samples. We use the 'Bayesian Optimization' module (http://rmcantin.github.io/bayesopt/html/bopttheory.html) to select the best hyperparameters in driving RF algorithm. Four critical parameters deciding the RF algorithm include the number of trees (n_estimators), the maximum tree depth (max_depth), the minimum number of samples for splitting an internal node (min_samples_split), and the number of features (max_features). For each specific climate region, the Bayesian optimization process is carried out within 20 iterations to optimal parameters. The training procedure is mainly based on the dataset covering 2003-2008. Optimal parameters in the seven climate regions are listed in Table 3.

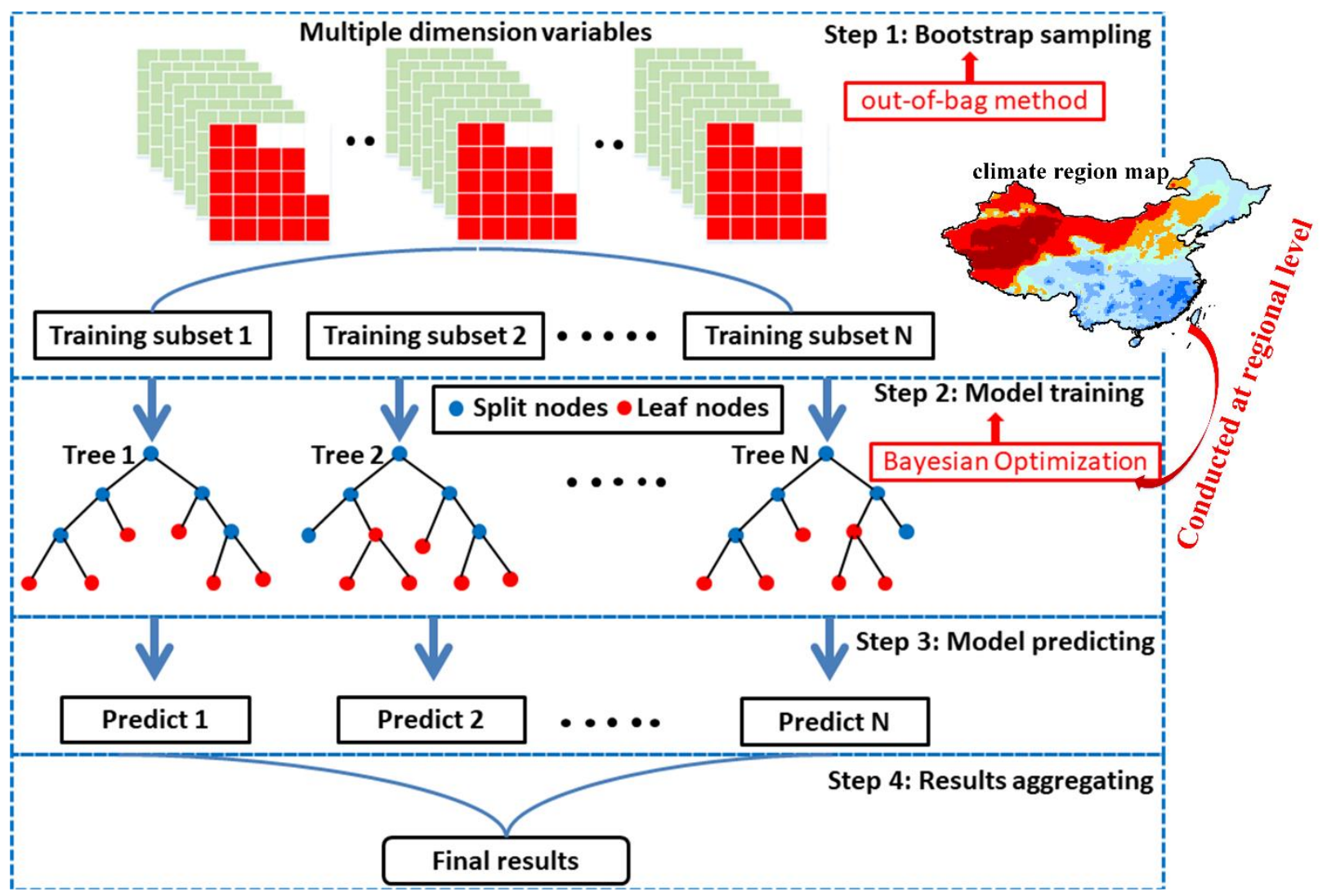

275 Figure 4: The diagram of the random forest model implemented for a multidimensional dataset. Stage 1: The out-of-bag sampling method is used to sample time series dataset. Stage 2: The independent decision trees for model training are built based on the optimal parameters from the Bayesian Optimization module. This process is conducted at the climate regional level. Stage 3: The predicted values are produced from each bootstrap tree. Stage 4: The outcome is obtained by averaging earlier results from multiple trees. 
Table 3 Optimal parameters regarding seven climate regions

\begin{tabular}{ccccc}
\hline \hline Climate region & n_estimators & max_depth & min_samples_split & max_features \\
\hline Arid & 69 & 11 & 8 & 0.12 \\
Semi-arid & 80 & 18 & 9 & 0.16 \\
Aird/semi-wet & 47 & 9 & 5 & 0.31 \\
Wet/semi-arid & 36 & 10 & 3 & 0.25 \\
Wet & 52 & 15 & 11 & 0.16 \\
Moist & 62 & 10 & 9 & 0.12 \\
Over-wet & 22 & 8 & 4 & 0.27 \\
\hline \hline
\end{tabular}

\subsection{Spatiotemporal strategy}

One critical issue of the machine learning model is how to efficiently explore the informative covariates. Here we use one spatiotemporal strategy to most capture the spatial and temporal SM and the related covariate dynamics. Our strategy primarily relies on the available pixels within one regional subset, thus including more interest pixels to participating regression. Figure 5(a) provides the diagram of the spatiotemporal window search strategy.

One adaptive strategy is employed to determine the optimal spatiotemporal window size. Two critical variables are adopted to identify the window size, i.e., the size of the spatial window (sw) and the number of temporal days (nd). To find the optimal sw and nd, we continually increase the value of sw and nd from the initial values until the samples participating for regression meet the criterion, i.e., the number of available pixels within the searched window should be no less than eight times of the participating explanatory variables (i.e., seven) (Svetnik et al., 2003; Liu et al., 2020a). Here an initial sw is set to 5 and an initial nd is set to 1 . Considering that a fraction of gaps occur in the satellite dataset (e.g., LST and albedo) and the optimal window may not exist, the maximum values of sw and nd are introduced to terminate this process. One sensitivity analysis is conducted with the independent dataset to select the two maximum values. Specifically, we conduct one cross validation during 2003-2008 to evaluate the accuracy of the gap-filling model. The increasing maximum nd from 1 to 7 with intervals of length 1 is tested, and the maximum sw is tested from 4 to 10 with intervals of length 1 . The values that yield the lowest RMSE (Fig. 5(b)) are selected, and finally, we set maximum sw to 7 and the maximum nd to 4 . Note that we also conduct sensitivity analysis for each climate region and find no substantial differences in the resulting optimal

300 values of two parameters among seven climate regions. This is probably because this sensitivity analysis is more reliant on model structure rather than sample characteristics. 


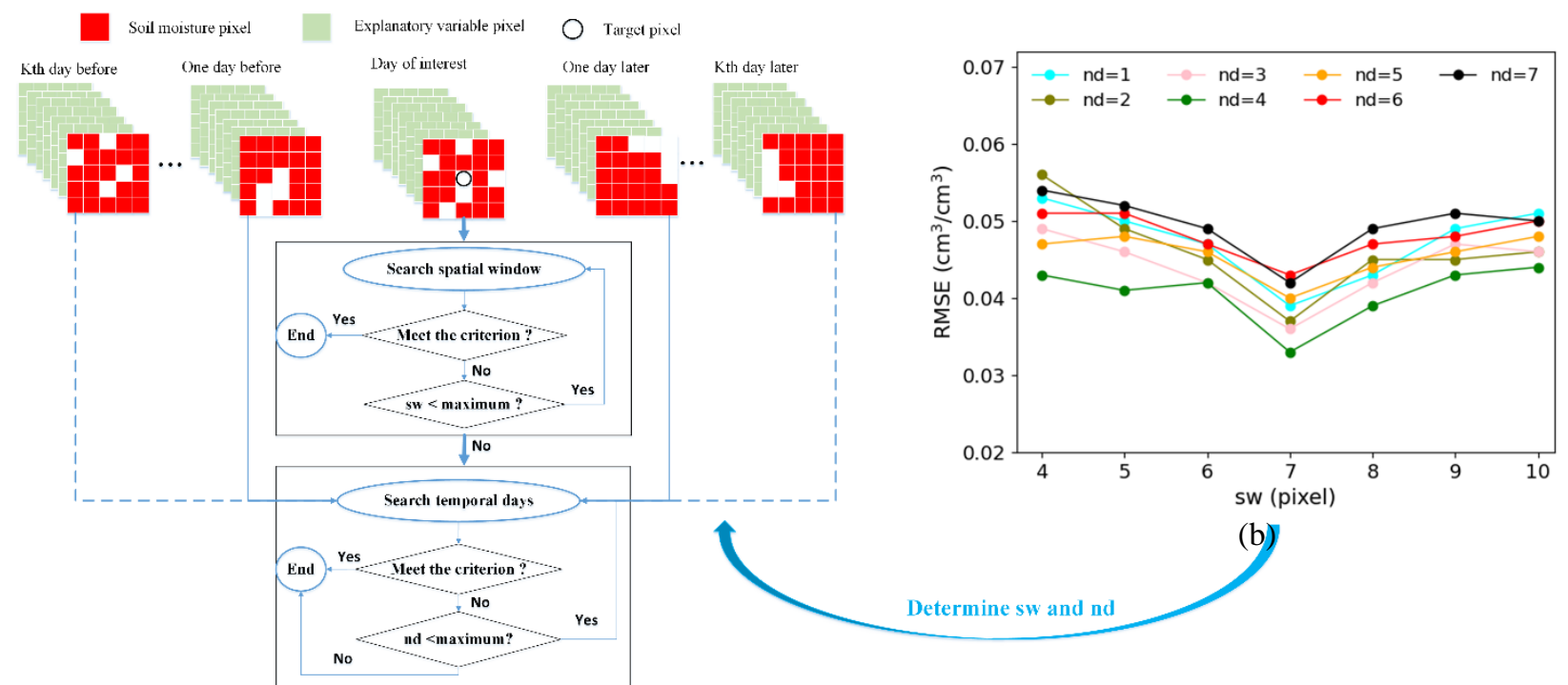

(a)

Figure 5: (a) The diagram of spatiotemporal window determination strategy for random forest regression. (b) The results of the sensitive analysis regarding two maximum values for terminating the searching process.

\subsection{Residuals calibration}

Considering the machine learning model may not fully account for the variability in soil moisture, the original reconstruction needs to be calibrated with the corresponding model residuals. The calibration procedure can correct the bias resulting from neglectful variables (Zhu et al., 2012; Liu et al., 2020a). This is very critical considering the relatively less spatial representative of soil moisture within the $25 \mathrm{~km}$ scale. In practice, we add the interpolated residuals to the original reconstructions.

A GWR model (Li et al., 2017) is applied to interpolate the RF-derived residuals. This procedure is based on the samples within the searched window for each target pixel. The model residual $\left(\varepsilon_{j}\right)$ derived from Eq. (2) can be described using the explanatory variables as follows:

$\varepsilon_{j}=\beta_{0}\left(u_{j}, v_{j}\right)+\sum_{i=0}^{k} \beta_{i}\left(u_{j}, v_{j}\right) X_{i j}$

315 where $\beta_{0}\left(u_{j}, v_{j}\right)$ and $\beta_{i}\left(u_{j}, v_{j}\right)$ are the regression coefficients estimated at the $j$ th pixel, and $\left(u_{j}, v_{j}\right)$ are the coordinates. The regression coefficients can be estimated using the observations within the self-adaptive searched window as follows:

$$
\left\{\begin{array}{rl}
\hat{\beta}\left(u_{j}, v_{j}\right)= & \left(X^{T}\left(W\left(u_{j}, v_{j}\right)\right) X\right)^{-1} X^{T} W\left(u_{j}, v_{j}\right) Y \\
& w_{i j}=\left[1-\left(d_{i j} / b\right)^{2}\right]^{2}
\end{array},\right.
$$

where $\hat{\beta}\left(u_{j}, v_{j}\right)$ is the coefficient matrix composed of coefficients from each explanatory variable; $X$ and $Y$ are the explanatory variable matrix and the dependent variable (i.e., SM) vector, respectively. Her latitude, longitude and seven 
explanatory variables selected in section 3.1.1 are used to implement the GWR model. $W\left(u_{j}, v_{j}\right)$ is the weight matrix composed of $w_{i j}, d_{i j}$ is the Euclidean distance between the observation $i t h$ and the $j$ th point, a and $b$ is the window radius. Before adding to the original reconstruction, the GWR interpolated residual is further smoothed with a normalized $\mathrm{k} \times \mathrm{k}$ Gaussian filter with a standard deviation of $\sigma$. This procedure can remove the grid-like artifacts that extensively exist in statistical model outcomes. Base on the optimization procedure (Sismanidis et al., 2021; Liu et al., 2019), we set $\mathrm{k}=5$ and $\sigma$ $325=1.5$.

\subsection{Accuracy evaluation}

The top layer (Table 2) SM measurements from in situ stations are used to evaluate the accuracy of the reconstructed results. Considering the scale mismatch between the sparse in situ station and CCI SM product ( $25 \mathrm{~km})$, we use the Disaggregation based on Physical And Theoretical scale Change (DISPATCH) model (Merlin et al., 2012) to disaggregate the $0.25^{\circ}$ reconstructions to $1 \mathrm{~km}$ resolution. As one typical SM disaggregation model, DISPATCH has been extensively applied in current studies (Molero et al., 2016; Song et al., 2021). In DISPATCH, SM can be depicted at different spatial scales by linking to LST and NDVI through soil evaporative efficiency. Detailed descriptions regarding this disaggregation method can be found in Supplementary Text S1.

In addition to field measurements, one holdout cross-validation with ten replicates is conducted to comprehensively evaluate

335 the model performance. For each replicate, we separate the dataset (CCI SM and explanatory variables) into the training (90\%) and the test subsets (10\%). After the gap-filled SM series are produced with the training set, they will be validated with the test set. The above cross-validation is also applied to conduct model comparison and uncertainty analysis.

The statistics used for the model accuracy assessment include the coefficient of determination $\left(\mathrm{R}^{2}\right)$, the root mean square error (RMSE), the mean absolute error (MAE), the average error bias (BIAS), and the unbiased RMSE (ubRMSE). All these

340 metrics have been extensively used for evaluating satellite SM, and they can be described as follows:

$R^{2}=1-\frac{\sum_{i}^{k}\left(S M_{i}-\widehat{S M}_{l}\right)}{\sum_{i}^{k}\left(S M_{i}-\widehat{S M}\right)}$

$R M S E=\sqrt{\frac{\sum_{i}^{k}\left(S M_{i}-\widehat{S M}_{l}\right)^{2}}{k}}$,

$M A E=\frac{\sum_{i}^{k}\left|S M_{i}-\widehat{S M}_{l}\right|}{k}$,

$B I A S=\frac{\sum_{i}^{k}\left(\widehat{M}_{l}-S M_{i}\right)}{k}$,

$345 u b R M S E=\sqrt{R M S E^{2}-B I A S^{2}}$,

where $S M_{i}$ is the reconstructed soil moisture of the $i$ th sample, and $\widehat{S M}_{l}$ is the corresponding reference (or field) value, $k$ is the number of samples. 
https://doi.org/10.5194/hess-2022-76

\section{Results and discussions}

\subsection{Spatiotemporal patterns}

350 The spatiotemporal pattern of the original daily CCI SM and the corresponding gap-filled dataset in 2009 is first checked. As shown in Fig. 6(a) (and (Fig. S3)), a considerably large gap occurs in the original CCI SM, and this gap issue is heavier in the winter season. We reconstruct the contaminated SM pixels using the spatiotemporal random forest model. It's observed that most of the contaminated pixels (more than 85\%) are reconstructed. Relatively fewer missing pixels are gap-filled in the winter season in comparison to other seasons, primarily relating to the heavy missing issues during this time.

355 Figure 6(b) shows the boxplot of original versus gap-filled SM on the selected days in 2009. Relative minor conformity exists between the original and reconstructed SM for most days. A consistent pattern between them is also observed on the monthly-average SM, as illustrated in Fig. 6(c). Large differences occur in the winter and spring seasons. This can be attributed to the fact that the original CCI SM provides less training data from October to May of the following year. In addition, the distribution of CCI SM is more uneven in this period, which may reduce the model performance due to the 360 limited representation of training samples (Stroud et al., 2001).

We further check the model performance regarding different climate regions. Figure 6(d) demonstrates one minor discrepancy between the original and the reconstructed SM, with the bias in median SM values less than 8\%. This means the reconstructed SM owns a strong variation delineating capacity. A small overestimation occurs for the arid regions, which originally have less soil water storage. 

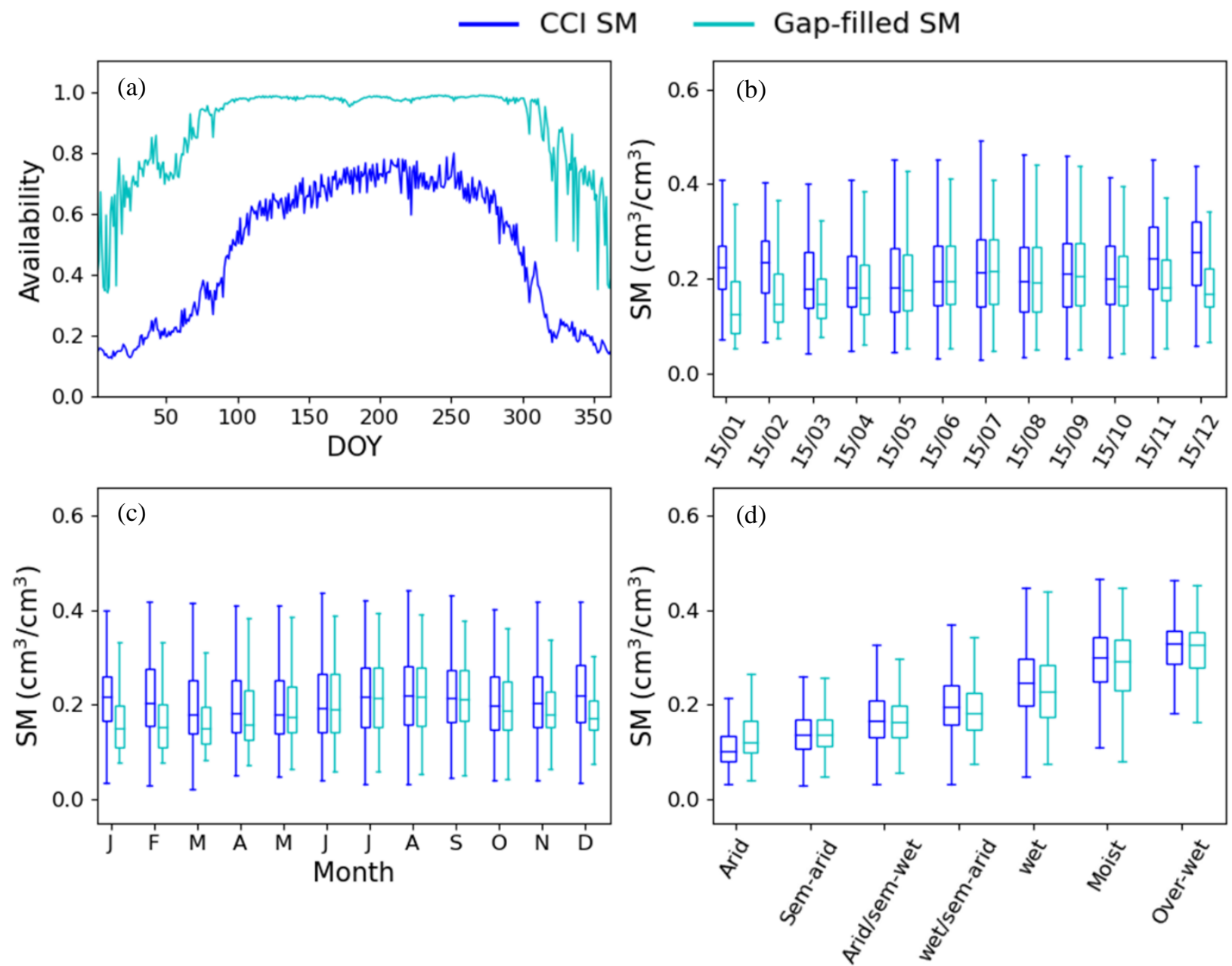

Figure 6: The comparison between CCI dataset and gap-filled SM in 2009. (a) The plots of the availability of CCI dataset and gapfilled SM. (b) The boxplot of the CCI dataset and gap-filled SM on the selected days. (c) The boxplot of month-average CCI and gap-filled SM. (d) The boxplot of raw and gap-filled SM regarding seven climate regions.

Figure 7 exhibits the spatial distributions of the original CCI SM on the selected days in 2009. It's observed that the humid regions are mostly concentrated in southern China that is adjacent to the west coast of the Pacific, whereas the dry regions are mainly distributed in the northern and western parts. A considerable fraction of contaminated pixels is observed on the selected days, and this contamination issue is severe in the winter season and mountainous areas (e.g., Tibet Plateau and Mongolian Plateau). The spatial distributions of the reconstructed SM corresponding to the selected days are illustrated in Fig. 8. Almost all the contaminated pixels from March to October are reconstructed; meanwhile, the proposed model reconstructs the most contaminated pixels for the remaining months. Owing to the additional valid values provided by gapfilled pixels, more spatial variations are delineated in the reconstructed SM images. The missing pixels still occur in the reconstructed SM images especially in the cold seasons. Some of these invalidate pixels correspond to the snow and watercovered regions that have been beforehand removed. 

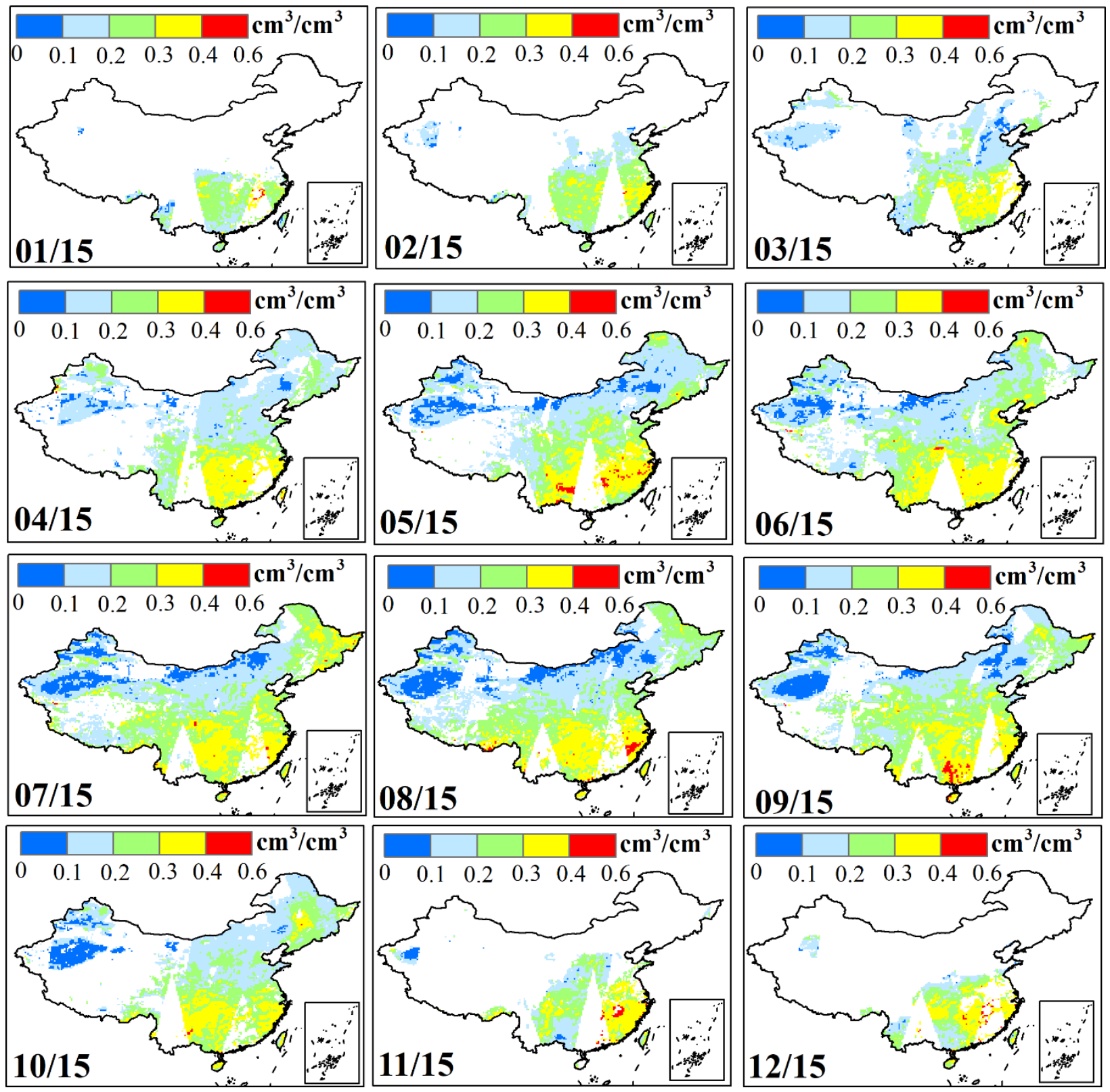

Figure 7: The spatial distributions of raw CCI SM on the 15th of each month in 2009. 

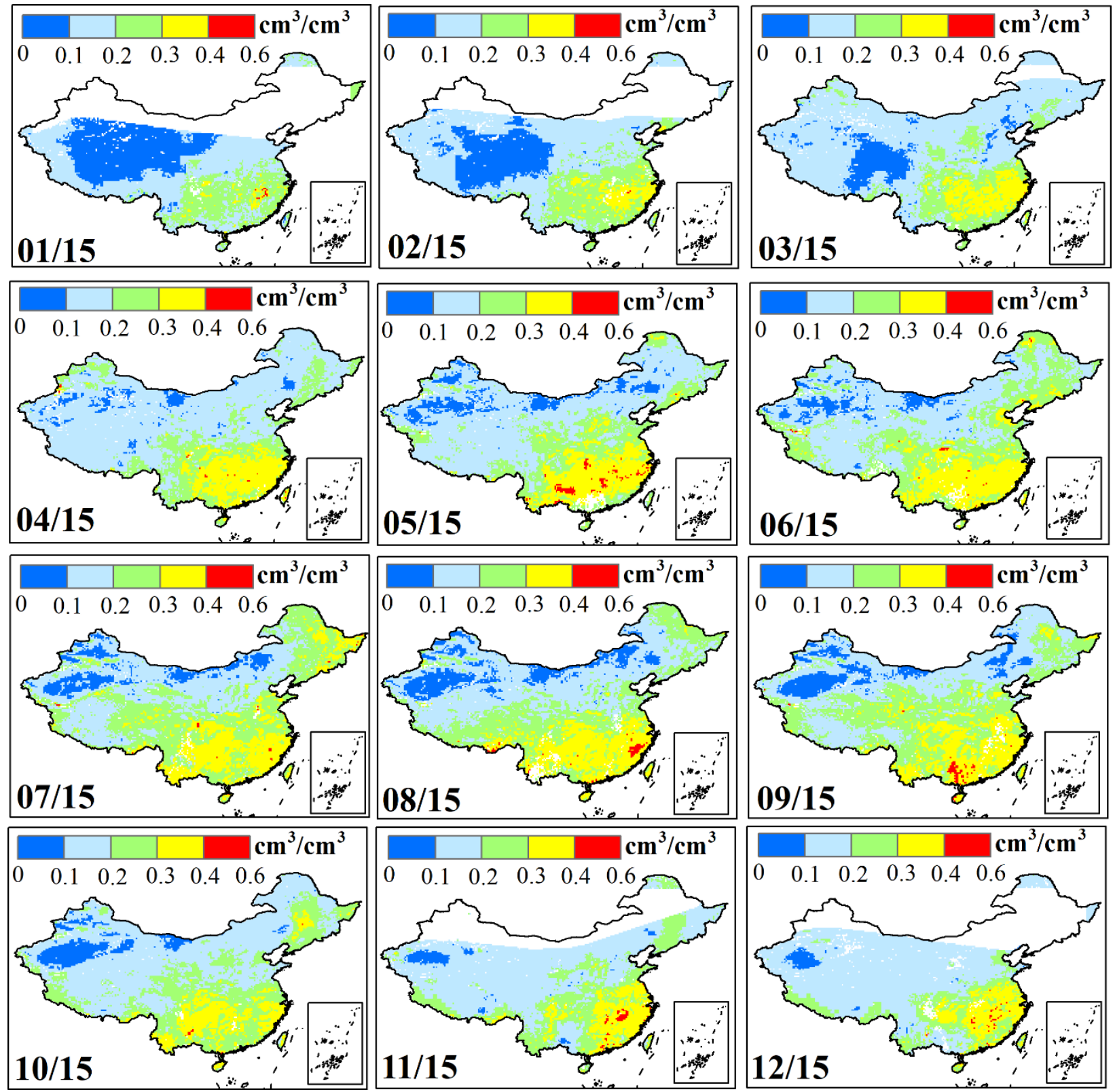

Figure 8: The spatial distributions of gap-filled CCI SM on the 15th of each month in 2009.

\subsection{Accuracy validation}

The proposed model is first evaluated with sparse in situ measurements from WATER and CERN. To avert the mismatch

issue, the $25 \mathrm{~km}$ SM dataset is disaggregated to $1 \mathrm{~km}$ using the DISPATCH model before accuracy validation. As shown in

Fig. 9(a), good accordance is obtained between $1 \mathrm{~km} \mathrm{CCI} \mathrm{SM-derived} \mathrm{values} \mathrm{and} \mathrm{in} \mathrm{situ} \mathrm{measurements,} \mathrm{with} \mathrm{an} \mathrm{R}^{2}$ of 0.8 .

This accordance is also found between the $1 \mathrm{~km}$ reconstructed SM and in situ measurements (Fig. 9(b)), with the $\mathrm{R}^{2}$ of 0.75 . 
Both the CCI SM-derived values and reconstructed SMs are close to the 1:1 line when evaluating with in situ measurements. High accuracies are observed when evaluating with in situ measurements from the national agro-meteorological stations.

390 Fig. 9(c) and (d) show the $\mathrm{R}^{2}$ between $1 \mathrm{~km} \mathrm{CCI} \mathrm{SM-derived} \mathrm{values} \mathrm{and} \mathrm{in} \mathrm{situ} \mathrm{measurements} \mathrm{is} 0.81$, while the $\mathrm{R}^{2}$ between $1 \mathrm{~km}$ reconstructed SM and in situ measurements is 0.71 . In general, our model is capacity in reconstructing SM. The inconsistency still exists, and noticeable overestimations are observed in high SMs.

We further validate the reconstructed results with the dense in situ measurements from the Maqu network. The RMSE and MAE is 0.11 and $0.09 \mathrm{~cm}^{3} / \mathrm{cm}^{3}$ (Fig. 9(e)) for the $1 \mathrm{~km} \mathrm{CCI} \mathrm{SM-derived} \mathrm{values,} \mathrm{respectively,} \mathrm{and} \mathrm{is} 0.12$ and $0.09 \mathrm{~cm}^{3} / \mathrm{cm}^{3}$ 395 (Fig. 9(f)) for the $1 \mathrm{~km}$ reconstructed SM, respectively. This means a good agreement is obtained for both the CCI SM product and gap-filled SM. The poor performance is found in the low values, mostly due to the extreme conditions and the fewer samples for model regression.

The time series of average $0.25^{\circ} \mathrm{CCI}$ SM values and reconstructed SM over the dense grid are compared to the dense in situ observations. Both the original and reconstructed SM matches well with the in situ series, with the NSE of 0.83 and 0.85 , respectively. The reconstructed SM (Fig. 9(g)) mostly describes the temporal dynamics of in situ measurements, i.e., sufficiently capturing seasonal and daily variability. It is also observed that the rainfall events impacting the surface dynamics are well delineated on the SM temporal variations. In general, the reconstructed SM seems to have inherited the merits of stability between April and November from CCI SM, i.e., having comparable values during this period. This is reasonable, since in addition to focusing on common explanatory variables such as Albedo, NDVI and DEM, our method introduces time series water-heat components, i.e., precipitation, PET, and reanalysis soil moisture, providing a substantial contribution in reconstructing time series SM. Meanwhile, since the used variables are daily, our model shows strong capacity in delineating abrupt climatic changes (Piles et al., 2016). 
https://doi.org/10.5194/hess-2022-76

Preprint. Discussion started: 4 March 2022

(c) Author(s) 2022. CC BY 4.0 License.
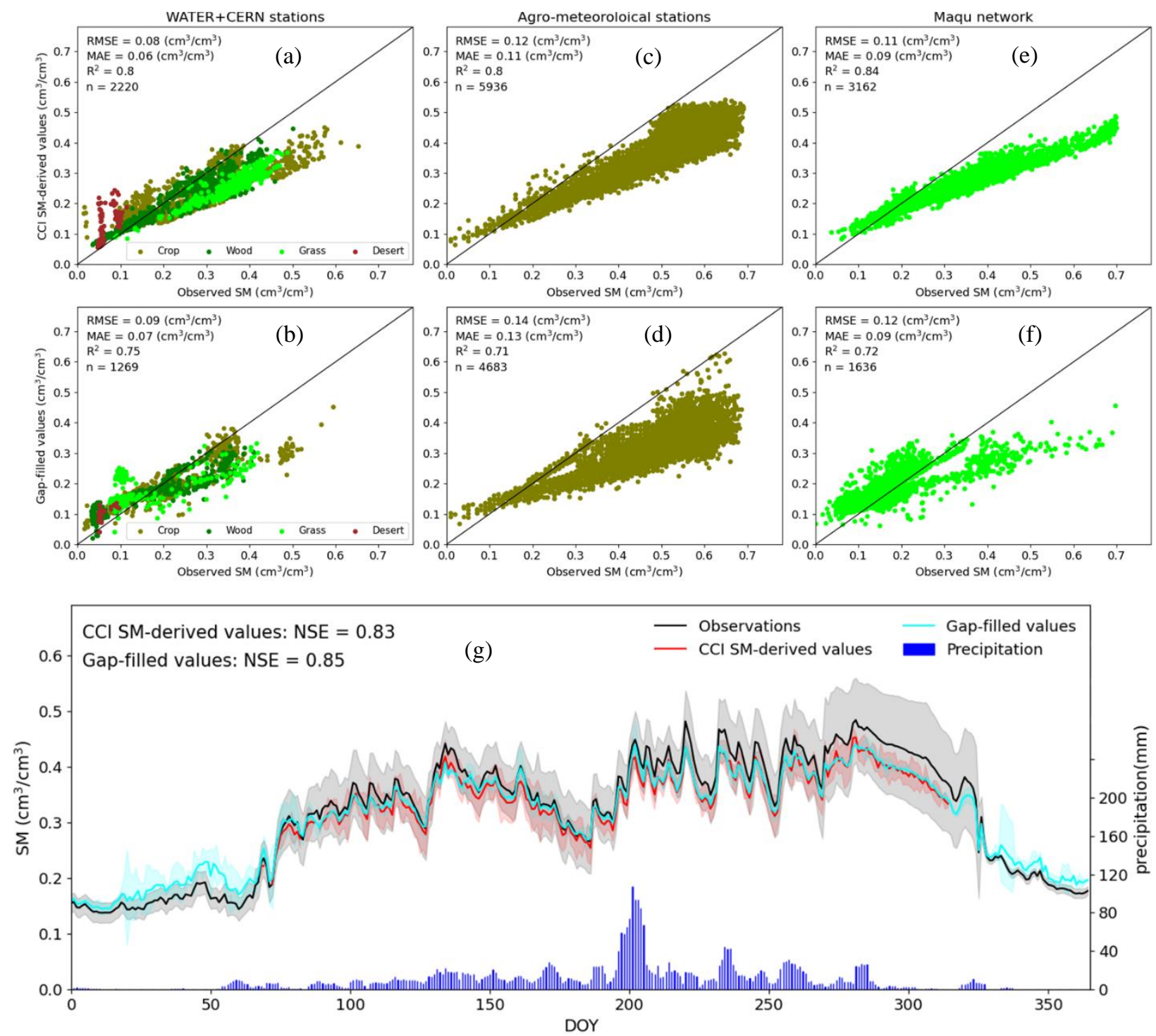

Figure 9: The evaluations of model results. (a), (c) and (e) are the scatter plots of 1-km CCI SM-derived values against field measures regarding WATER/CEERN, agro-meteorological stations, and Mauqu network, respectively, and (b), (d) and (f) are the scatter plots of 1-km gap-filled SM-derived values against field measures. (g) are the time series of average CCI SM-derived values against site measures in the Maqu region. The shaded area in $(\mathrm{g})$ denotes \pm 1 standard error.

One cross-validation analysis is further conducted to evaluate the model performance. The obtained metrics (Fig. 10(a)) illustrate a good coincidence between the reconstructed and original CCI SM, with the median $\mathrm{R}^{2}$ range between 0.51 and

0.63. Better accuracies are also demonstrated in the metrics of RMSE, MAE and ubRMSE. In particular, the medians of BIAS are less than $0.01 \mathrm{~cm}^{3} / \mathrm{cm}^{3}$. Relatively better accuracies happen in the growth seasons (March-October). This can be attributed to the fact that the critical environmental factors, such as NDVI, DTR and ERA soil moisture, are more related to soil moisture during the vegetation growing seasons (Chen et al., 2014; Otkin et al., 2016). 
https://doi.org/10.5194/hess-2022-76

Figure 10(b) shows the accuracy metrics for different climate regions. A similar pattern as those in monthly means is observed, i.e., acceptable accuracy occurs in most regions. No significant differences in median $\mathrm{R}^{2}$ and BIAS happen between the reconstructed SM of each climate region, with the bias between the maximum and minimum median $\mathrm{R}^{2}$ and BIAS being less than 0.09 and $0.003 \mathrm{~cm}^{3} / \mathrm{cm}^{3}$, respectively. The relatively poor performance of metrics (e.g., RMSE and MAE) in wet regions can be related to the high values in albedo and specific heat capacity (Guan et al., 2009). Meanwhile, the fewer amounts of available observations (i.e., LST and albedo) in these areas can affect the model capacity and stability. It should be noticed that, despite the relatively high RMSE, MAE and ubRMSE over the humid region, $\mathrm{R}^{2}$ is very high, as illustrated in Fig. 10. This might be due to the SM variability in these areas being high.
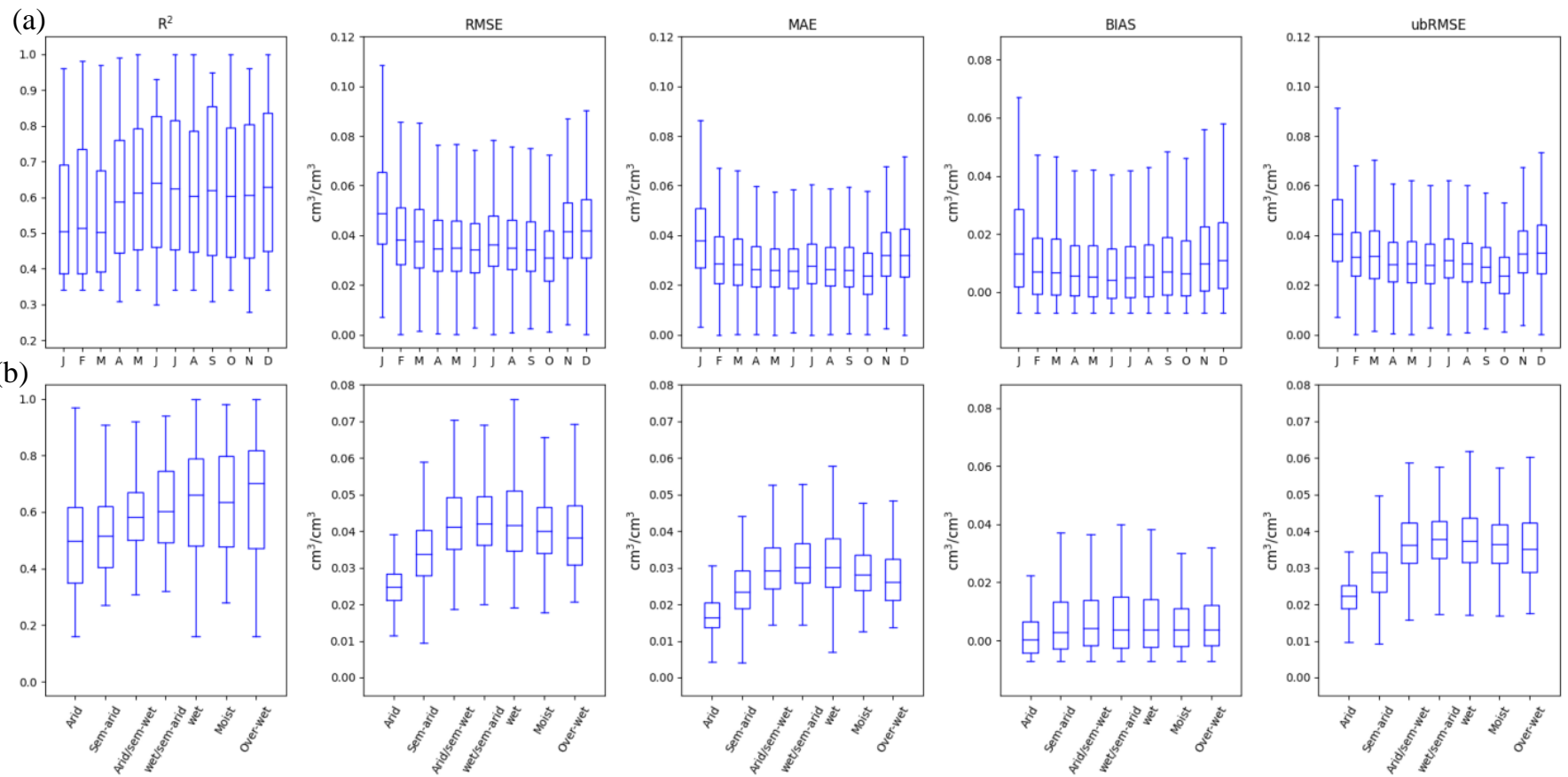

Figure 10: The accuracy metrics of 10-cross validation for R2, RMSE, MAE, BIAS, and ubRMSE: (a) is averagely obtained on a month basis, and (b) is averagely obtained for each climate region.

430 The spatial distributions of accuracy metrics in Fig. 11 further illustrate the good accuracy of the proposed gap-filling model. The obtained metrics in the cross-validation analysis show a good match between the reconstructed SM and the original SM CCI for most of the grids. Discrepancies are observed in some grids, but they rarely exceed $0.09 \mathrm{~cm}^{3} / \mathrm{cm}^{3}$ in absolute value. Spatially, the distribution of reconstructed SM follows a geographic gradient. The relatively lower accuracies occur on the complicated terrain in western China. For these regions, complex atmospheric conditions caused by high elevations tend to 435 affect the delineations of surface parameters. Meanwhile, complex topography may result in a complicated directional anisotropy, bringing more uncertainty in modeling surface energy and water cycles (Hu et al., 2016). 

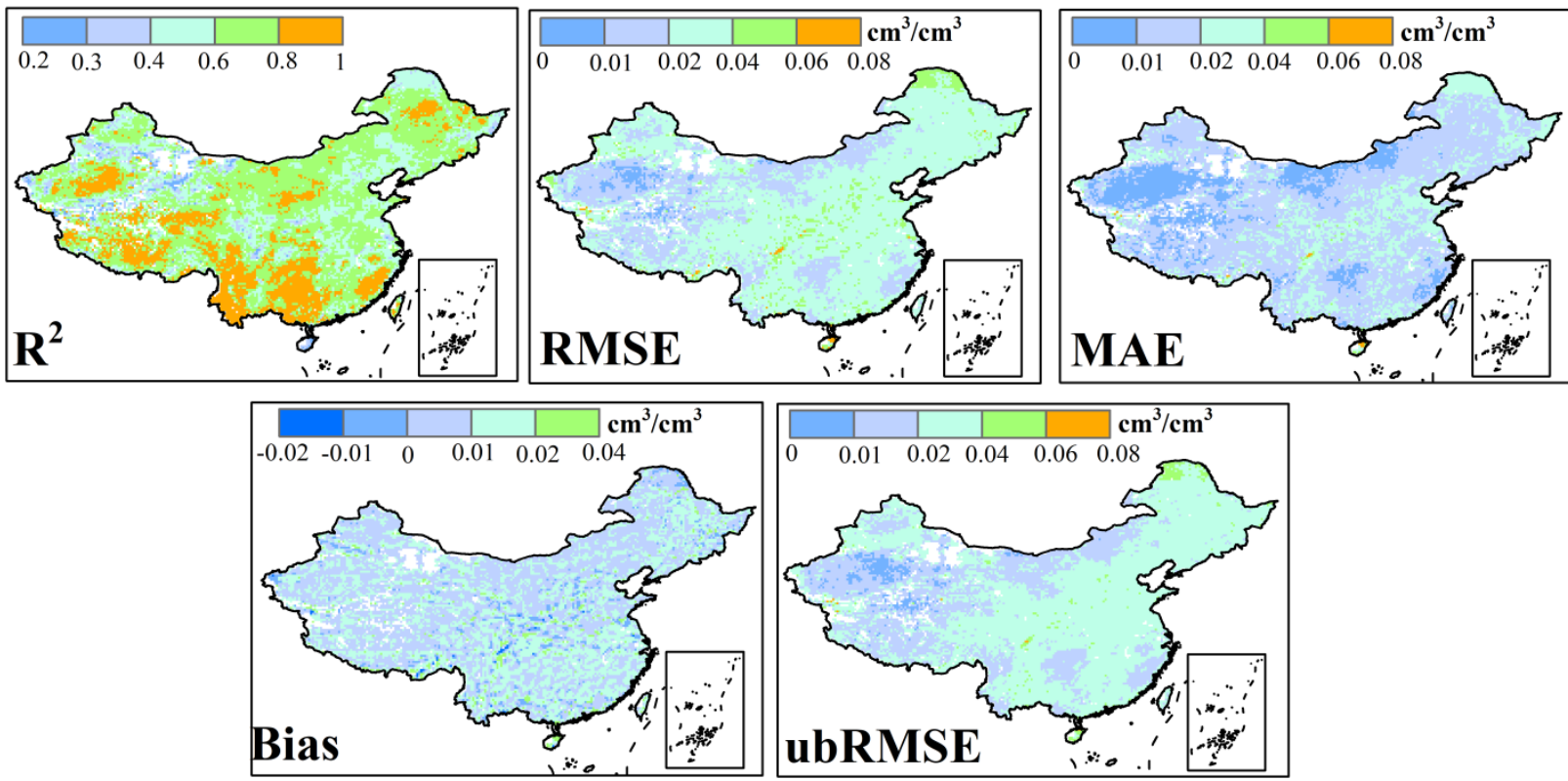

Figure 11: The spatial distributions of accuracy metrics of 10-cross validation in 2009 for R2, RMSE, MAE, BIAS, and ubRMSE.

\subsection{Comparison analysis}

440 To fully reveal the merits in modeling the critical surface characteristics, our model is further compared against previous studies, as illustrated in Table 4. In general, the accuracies produced by our model are comparable and even better than previous studies, despite being evaluated with different in suit measurements and simulated approaches. The satisfied performance of the proposed model is plausible, which can be attributed to the following aspects. Given the complex underlying surface and the diverse climatic conditions across one continuous scale, we chose more efficient explanatory variables relative to previous research. Especially, the land surface model and reanalysis outputs are introduced to bring additional context for overcoming the severe missing issues of remotely sensed variables. Simultaneously, an adaptive spatiotemporal domain strategy and residual calibration module are incorporated into machine learning to balance the regression performance, overfitting problems, and computational complexity. This strategy focuses on the covariates that include both the spatial and temporal domains, therefore possessing the potential of producing more reasonable accuracy compared to other approaches that utilize either spatial domain (Li et al., 2021a).

Table 4 The accuracy comparison among different literatures

\begin{tabular}{|c|c|c|c|c|c|c|c|}
\hline & \multirow{2}{*}{$\begin{array}{c}\text { SM } \\
\text { source }\end{array}$} & \multirow{2}{*}{ Model } & \multirow{2}{*}{ Adopted variables } & \multirow{2}{*}{$\begin{array}{c}\text { Study } \\
\text { Region }\end{array}$} & \multicolumn{2}{|c|}{ Accuracy } & \multirow{2}{*}{ Literatures } \\
\hline & & & & & Field-validation & simulation-validation & \\
\hline 1 & $\begin{array}{l}\text { ESA } \\
\text { CCI }\end{array}$ & $\mathrm{RF}$ & $\begin{array}{l}\text { LST, Precipitation, } \\
\text { NDVI, PET, Soil } \\
\text { texture }\end{array}$ & $\begin{array}{l}\text { Southern } \\
\text { Europe }\end{array}$ & & $\begin{array}{c}\text { RMSE }=0.024-0.025 \\
\mathrm{~m}^{3} / \mathrm{m}^{3}\end{array}$ & $\begin{array}{c}\text { Almendra- } \\
\text { Martín et al } \\
\text { (2021) }\end{array}$ \\
\hline
\end{tabular}




\begin{tabular}{|c|c|c|c|c|c|c|c|}
\hline 2 & $\begin{array}{l}\text { ESA } \\
\text { CCI }\end{array}$ & ANN & $\begin{array}{c}\text { Precipitation, } \\
\text { Temperature, NDVI, } \\
\text { LAI, DEM, Slope, } \\
\text { Aspect, Latitude, } \\
\text { Longitude, Soil texture }\end{array}$ & China & $\begin{array}{c}\text { RMSE }=0.036-0.074 \\
\mathrm{~m}^{3} / \mathrm{m}^{3}\end{array}$ & $\begin{array}{c}\text { RMSE }=0.037-0.064 \\
\mathrm{~m}^{3} / \mathrm{m}^{3}\end{array}$ & $\begin{array}{l}\text { Zhang et al. } \\
\text { (2021b) }\end{array}$ \\
\hline 3 & $\begin{array}{l}\text { ESA } \\
\text { CCI }\end{array}$ & $\mathrm{RF}$ & $\begin{array}{l}\text { NDVI, LST, Daytime } \\
\text { LST, Nighttime LST, } \\
\text { Diurnal LST }\end{array}$ & $\begin{array}{c}\text { Oklahoma } \\
\text {, USA }\end{array}$ & $\mathrm{RMSE}=0.08 \mathrm{~m}^{3} / \mathrm{m}^{3}$ & $\mathrm{RMSE}=0.02 \mathrm{~m}^{3} / \mathrm{m}^{3}$ & $\begin{array}{l}\text { Liu et al. } \\
\text { (2020b) }\end{array}$ \\
\hline 4 & AMSR2 & $\mathrm{CNN}$ & I & Global & $\mathrm{RMSE}=0.097 \mathrm{~m}^{3} / \mathrm{m}^{3}$ & $\begin{array}{c}\text { RMSE }=0.065-0.073 \\
\mathrm{~m}^{3} / \mathrm{m}^{3}\end{array}$ & $\begin{array}{l}\text { Zhang et al. } \\
\text { (2021c) }\end{array}$ \\
\hline 5 & $\begin{array}{l}\text { ESA } \\
\text { CCI }\end{array}$ & $\begin{array}{l}\text { MLR, OK, } \\
\text { RK }\end{array}$ & $\begin{array}{l}\text { Precipitation, } \\
\text { Temperature }\end{array}$ & $\begin{array}{l}\text { Midwest, } \\
\text { USA }\end{array}$ & $\begin{array}{c}\text { RMSE }=0.067-0.070 \\
\mathrm{~m}^{3} / \mathrm{m}^{3}\end{array}$ & & $\begin{array}{l}\text { Llamas et al. } \\
\qquad(2020)\end{array}$ \\
\hline 6 & FY-3B & BP-NN & $\begin{array}{l}\text { LST, NDVI, Albedo, } \\
\text { Latitude, Longitude, } \\
\text { DEM, DOY }\end{array}$ & $\begin{array}{l}\text { Tibetan } \\
\text { Plateau }\end{array}$ & $\mathrm{RMSE}=0.1 \mathrm{~cm}^{3} / \mathrm{cm}^{3}$ & & $\begin{array}{l}\text { Cui et al. } \\
\text { (2016) }\end{array}$ \\
\hline 7 & $\begin{array}{l}\text { ESA } \\
\text { CCI }\end{array}$ & $\mathrm{RF}$ & $\begin{array}{c}\text { Albedo, NDVI, DTR, } \\
\text { AP, PET, ERA SM } \\
\text { and TPI }\end{array}$ & China & $\begin{array}{c}\text { RMSE }=0.09-0.14 \\
\mathrm{~cm}^{3} / \mathrm{cm}^{3}\end{array}$ & $\begin{array}{c}\text { RMSE }=0.025 \\
\mathrm{~cm}^{3} / \mathrm{cm}^{3}\end{array}$ & Our study \\
\hline
\end{tabular}

Note: $\mathrm{CNN}=$ Convolutional neural network, $\mathrm{OK}=$ ordinary kriging, RK = regression kriging, BP-NN = back-propagation neural network

The proposed method is future compared against four extensively used models that adopt the same explanatory variables and spatiotemporal window search strategy. The first one is the conventional multiple linear regression (MLR) approach. Three typical machine learning approaches, i.e., Extreme gradient boost (XGB), Support vector machine (SVM) and Artificial Neural Network (ANN), are also used for comparison. Detailed descriptions of four available models can be found in supplementary Text S2. The accuracy metrics of the five models are shown in Fig. 12. Generally, the MLR, XGB, SVM and ANN, accompanying RF, could potentially reconstruct the missing CCI SM pixels, indicating the stable suitability of these models and the feasibility of available variables. Moreover, the RF model demonstrates prominent performance among all the models, further manifesting its capacity in reconstructing soil moisture when integrating the effective dataset source and mining method. This is consistent with earlier studies that illustrate the robustness of RF in simulating satellite parameters (Karbalaye Ghorbanpour et al., 2021; Zhao et al., 2018). Based on this, we also check the accuracy of models excluding the residual calibration procedure, which is one essential procedure for the proposed model. Results in Fig. 12 demonstrate the accuracies are lowered by $~ 9 \%$ when removing residual calibration, underscoring the importance of residual modulation in 465 improving SM reconstructing. Meanwhile, the better performance brought by spatiotemporal domain strategy is also exhibited when compared with the global regression, as illustrated in Fig. 12. Quantitatively, the spatiotemporal domains can improve the accuracy of $\sim 19 \%$ in forcing RF regression. Overall, these analyses indicate the feasibility of the proposed model by integrating the modules of residual calibration and spatiotemporal domain strategy. 


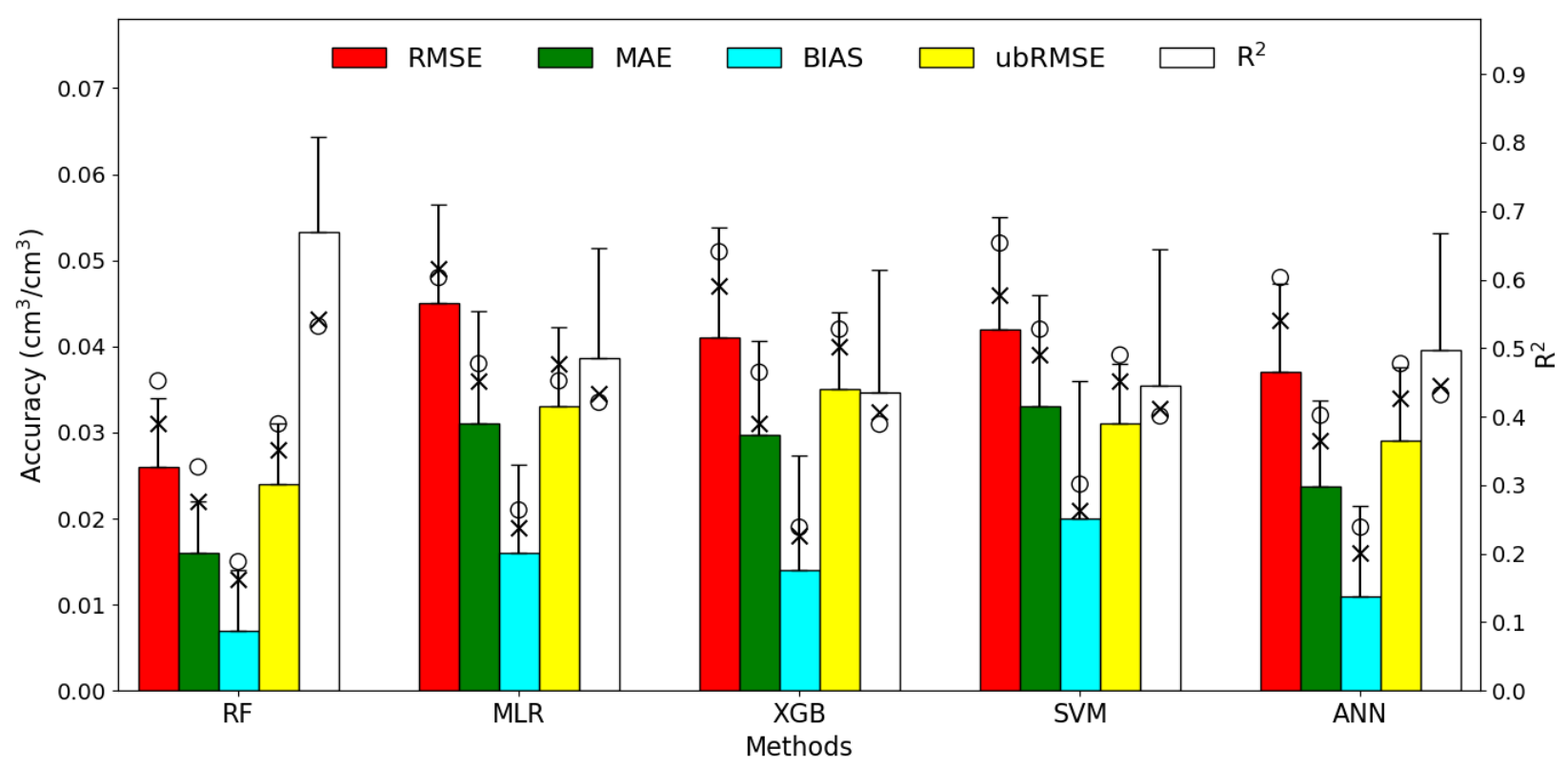

470 Figure 12: Comparison RF-based model with other models (i.e., MLR, XGB, SVM and ANN). Error bars denote 16 errors. The symbol ' $x$ ' represents the accuracy metrics of models excluding the residual calibration procedure, and the symbol ' 0 ' represents the accuracy metrics of the models that use the global regression rather than regional regression based on the spatiotemporal window searching strategy.

\subsection{Importance analysis}

475 Considering the criticality of explanatory variables in simulating SM, importance analyses regarding these selected variables are conducted. We first investigate the accuracy of the reconstruction model that excludes one participating variable. As illustrated in Fig. 13(a), the performance of the model with six variables (i.e., excluding one) is relatively lower when compared with that with seven variables. The removing-one strategy can lower the accuracies of $2.2-6.4 \%$ in $\mathrm{R}^{2}$ and $10-30 \%$ in BIAS. This diminished performance is plausible since SM is heavily related to all the selected variables. Specifically, variability in land surface characteristics (NDVI and albedo) and atmospheric conditions (i.e., precipitation and PET) can heavily impact the soil moisture variability. Meanwhile, additional covariates mean an increase in the number of samples participating in the regression model, therefore potentially resulting in an improvement of overall accuracy. Specifically, we observe the lowest accuracy occurs when DTR is excluded, underscoring the vital role of DTR in modeling SM.

We further investigate the contribution of each explanatory variable in modeling SM. The importance score produced by the

$485 \mathrm{RF}$ algorithm itself is used to delineate relative contribution (Zhao et al., 2019b; Ramoelo et al., 2015). As demonstrated in Fig. 13(b) (and Fig. S4), AP and ERA SM substantially impact CCI SM modeling, with the average importance score of 0.48 and 0.47, respectively. The NDVI, albedo, TPI and PET have less importance with the average score of 0.41, 0.43, 0.42 and 0.45 , respectively. Specifically, the DTR shows the highest importance with an average score of 0.52 . This is mainly related to the fact that temperature variations likely have a far-reaching influence on soil moisture fluctuation. The heat from the 
https://doi.org/10.5194/hess-2022-76

surface can be transferred to the atmosphere via evapotranspiration and sensible heat conduction, thereby modifying surface soil moisture variations (Amani et al., 2017).
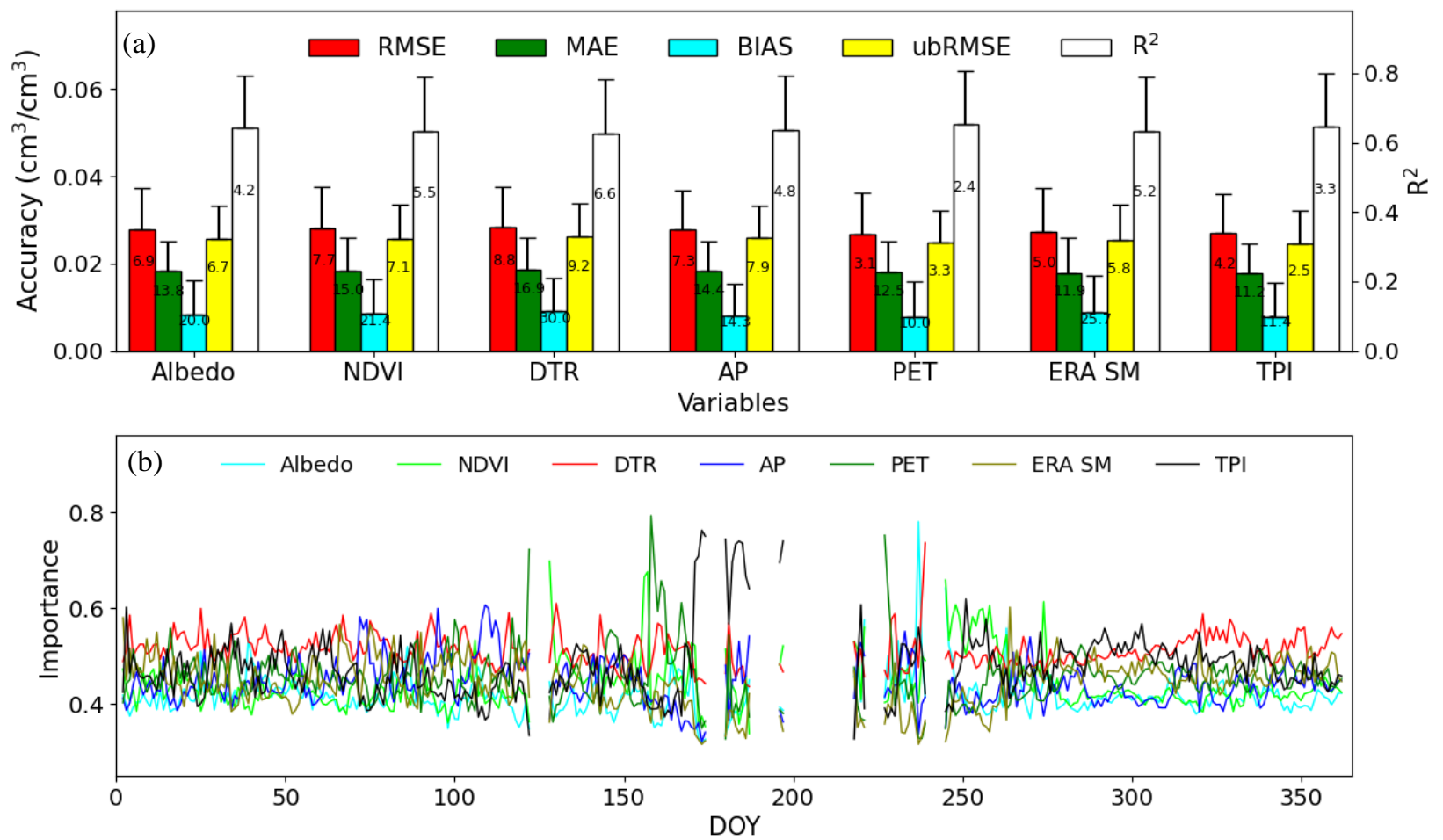

Figure 13: (a) The accuracy of the models removing one variable, i.e., using other six variables in model regression. Error bars denote $1 \sigma$ errors. The text denotes the relative percentage of the lowered accuracy in comparison to those using all seven variables. (b) The importance score of the selected variables derived from RF regression.

\subsection{Uncertainty analysis}

Given the critical importance of satellite-derived DTR and the severe missing issues in satellite-observed LST products, we further investigate the substitution performance of other surface temperature sources in reconstructing SM, i.e., i.e., Noah, ERA and GLDAS. This analysis is conducted at two focused regions (in Fig. 1) that have sufficient data sources supporting our experiments: one region is in northern China that is mostly occupied by arid and semi-arid areas, while the other region is in southern China that is occupied by wet areas. Considering the bias between satellite LST and modeled surface temperature, the variable correction described in section 3.1.2 is conducted to remove the systematic bias and make the simulated DTR comparable to satellite observations.

Figure 14(a) shows the minor reductions in Pearson correlation and RF-derived importance score of three numerical model simulated DTRs when comparing with MODIS-derived DTR, which indicates the feasibility of all these datasets in reconstructing SM. Fig. 14(b) and (c) illustrate noticeable reductions in model accuracy when replacing the satellite LST with the other three simulated sources. Regarding the accuracy metric, the RMSE of reconstructed SM can be reached to $0.0282,0.0299$ and $0.0303 \mathrm{~cm}^{3} / \mathrm{cm}^{3}$, when respectively using Noah, ERA and GLDAS-simulated DTR over the northern 
region. As for southern China, the RMSE of reconstructed SM can be reached $0.0342,0.0353$ and $0.0357 \mathrm{~cm}^{3} / \mathrm{cm}^{3}$, when respectively using the other three dataset. Nevertheless, the availability of reconstructed SM products is remarkably increased (by $\sim 6-11 \%$ ) due to the all-weather coverage of reanalysis and land surface model simulations. This suggests the surface temperature source from the numerical model dataset can be one alternative for satellite LST, which is essential at one long-term and large extended scale, especially considering their full coverage attribution. On the other hand, as illustrated in Fig. 14 (b) and (c), one noticeable reduction in accuracy metric ( 4\%) occurs when not considering the variable correction procedure. This emphasizes the indispensable contribution of variable calibration procedures in reconstructing surface characteristics (Duan and Bastiaanssen, 2013; Liu et al., 2020a).

Since the reanalysis SM is one vital input in our approach, we also compare it with the other two products to evaluate the feasibility of ERA data in reconstructing CCI SM. GLEAM and Noah surface SM are respectively employed to replace the ERA SM while other explanatory variables keep the rest the same. Although the GLEAM and Noah SM-based schemes can demonstrate acceptable accuracies, they exhibit slightly inferior accuracies compared to ERA SM-based schemes (Fig.14 (b) and (c)), probably due to their relatively large uncertainties in delineating the surface soil moisture dynamics across the two selected regions (Mahto and Mishra, 2019; Chen and Yuan, 2020). Nevertheless, considering our study merely focuses on two local regions, we cannot manifest that the ERA product could provide the best performance across China. More attention should be focused on further work.
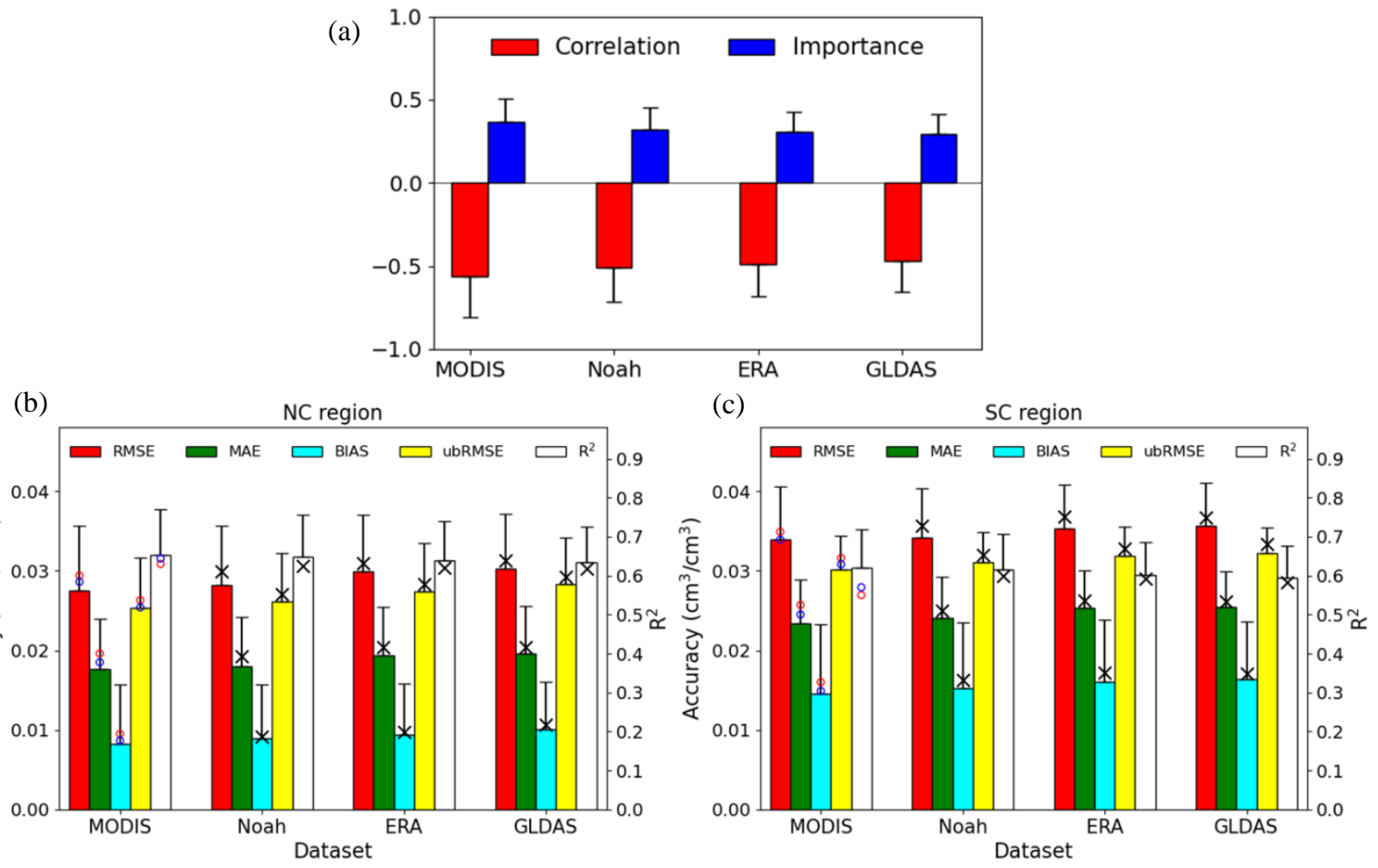
https://doi.org/10.5194/hess-2022-76

Hydrology and

Preprint. Discussion started: 4 March 2022

(C) Author(s) 2022. CC BY 4.0 License.

Figure 14: The performance of models using Noah, ERA, and GLDAS DTR replacing MODIS DTR. (a) The Pearson correlation and importance score of DTRs. (b) and (c) The metrics of models using different DTRs for Northern China (NC) and Southern China (SC), respectively. Error bars denote $1 \sigma$ errors. The symbol ' $x$ ' represents the accuracy metrics of the models without DTR correction procedure. The symbol ' $o$ ' in red represents the accuracy metrics of the models using GLEAM SM to replace ERA SM, and the symbol ' 0 ' in blue represents the accuracy of the models using Noah SM to replace ERA SM.

\subsection{Extending to one long-term scale}

The available dataset forcing our model has a long sequence, implying one potential in modeling long-term SM products. To verify this, the proposed gap-filling method is further extended to the long-term ECA CCI SM databases. During 20052015, more than $90 \%$ of the contaminated pixels can be reconstructed using our model, as illustrated in Fig. 15(a) and (b).

When evaluating the pixels against dense in situ measurements in the Maqu network, we observe that the reconstructed SM has comparable accuracy with the original SM (Table 5). The average $\mathrm{R}^{2}$ and RMSE of reconstructed SM are 0.73 and 0.12 $\mathrm{cm}^{3} / \mathrm{cm}^{3}$, respectively. The present results indicate the proposed model has a strong capacity to simulate SM at a long-time scale.

Figure 15(c) shows obvious differences between the gap-filled and original SM dataset. Negative differences in SM occur in most regions, while positive differences happen in a small fraction of the wet and arid regions. The dynamic and trend of SM are fundamental to assessing and quantifying eco-hydrology regime. Accordingly, we further investigate the trend of SM series during 2005-2015, which is obtained with Sen's slope and M-K significant analysis (Li et al., 2021b; Liu et al., 2021a). As shown in Fig. 15(d)-(f), the difference in valid SM values participating in trend analysis brings about a noticeable disparity in SM trend, which implies a slightly decreased SM trend for most arid regions in China and an increased SM trend

545 for most humid regions. This pattern in SM trend is mostly related to the climate changes (precipitation and temperature) changes and human activities (Li et al., 2018b).

The biases in SM dynamic and trend are more pronouncedly delineated for each climate region in Fig. 16(a) and (b). Results show that the trends from the reconstructed SM are relatively lower compared to those from the original CCI SM. The improvement of the reconstructed dataset in depicting SM trends are quantitatively manifested in Fig. 16(c) and (d), which demonstrates the $\mathrm{R}^{2}$ between the trends from the original CCI SM and those from in situ measurement is 0.23 while the $\mathrm{R}^{2}$ between the trends from the reconstructed CCI SM and those from observations is increased to 0.45. Overall, an effective gap-filled model is demanded considering its capacity in fully depicting dynamics and trends of SM.

Table 5 Metrics for the gap-filling performance regarding Maqu network for the extended years

\begin{tabular}{ccccccccccccc}
\hline \hline \multirow{2}{*}{ Year } & \multicolumn{4}{c}{ Metrics for raw CCI dataset } & \multicolumn{4}{c}{ Metrics for gap-filled dataset } \\
& $\mathrm{R}^{2}$ & RMSE & MAE & Bias & ubRMSE & NSE & $\mathrm{R}^{2}$ & RMSE & MAE & Bias & ubRMSE & NSE \\
\hline 2008 & 0.8 & 0.11 & 0.1 & 0.06 & 0.06 & 0.8 & 0.71 & 0.13 & 0.13 & 0.07 & 0.06 & 0.81 \\
2010 & 0.82 & 0.1 & 0.09 & 0.05 & 0.06 & 0.81 & 0.73 & 0.11 & 0.11 & 0.06 & 0.05 & 0.83 \\
2011 & 0.83 & 0.09 & 0.09 & 0.06 & 0.06 & 0.82 & 0.74 & 0.11 & 0.1 & 0.06 & 0.05 & 0.84 \\
2012 & 0.81 & 0.12 & 0.09 & 0.06 & 0.05 & 0.81 & 0.72 & 0.13 & 0.12 & 0.05 & 0.05 & 0.82 \\
2013 & 0.82 & 0.09 & 0.09 & 0.06 & 0.05 & 0.8 & 0.73 & 0.12 & 0.13 & 0.07 & 0.07 & 0.82
\end{tabular}


https://doi.org/10.5194/hess-2022-76

Preprint. Discussion started: 4 March 2022

(c) Author(s) 2022. CC BY 4.0 License.
Hydrology and

Earth System

Sciences

Discussions

$\begin{array}{ccccccccccccc}2014 & 0.85 & 0.09 & 0.08 & 0.06 & 0.05 & 0.83 & 0.74 & 0.11 & 0.09 & 0.08 & 0.06 & 0.85 \\ 2015 & 0.79 & 0.12 & 0.1 & 0.07 & 0.07 & 0.79 & 0.69 & 0.14 & 0.12 & 0.09 & 0.07 & 0.81\end{array}$

Note: NSE is from the evaluation with the time series of average $0.25^{\circ}$ pixels while the other five metrics are from the evaluation with 1
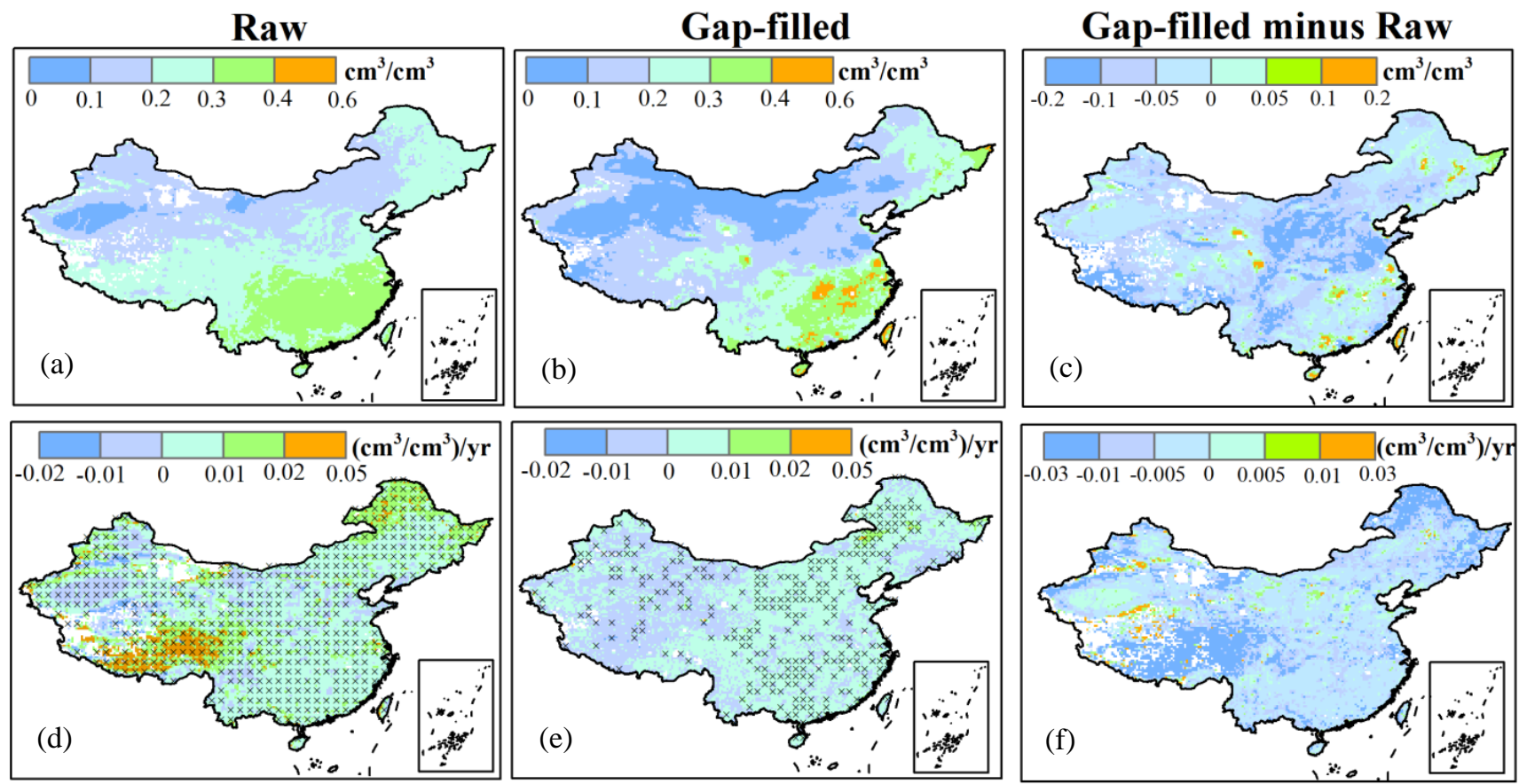

Figure 15: The implementation of the proposed model to 2005-2015. (a) and (b) are the average values of raw CCI and gap-filled SM during 2005-2015, and (c) is the difference between them. (d) and (e) are the average trends of raw CCI and gap-filled SM during 2005-2015, and (f) is the difference between them. The symbol " $x$ " in (d) and (e) denotes the significance level under 0.05 . 

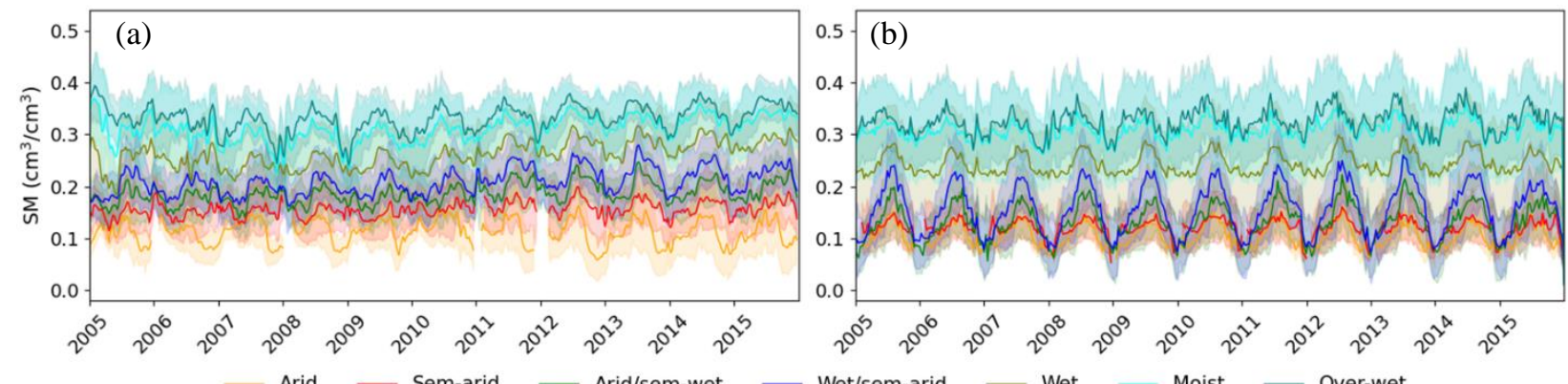

Arid $\longrightarrow$ Sem-arid $\quad$ Arid/sem-wet

- Wet/sem-arid — Wet Moist - Over-wet
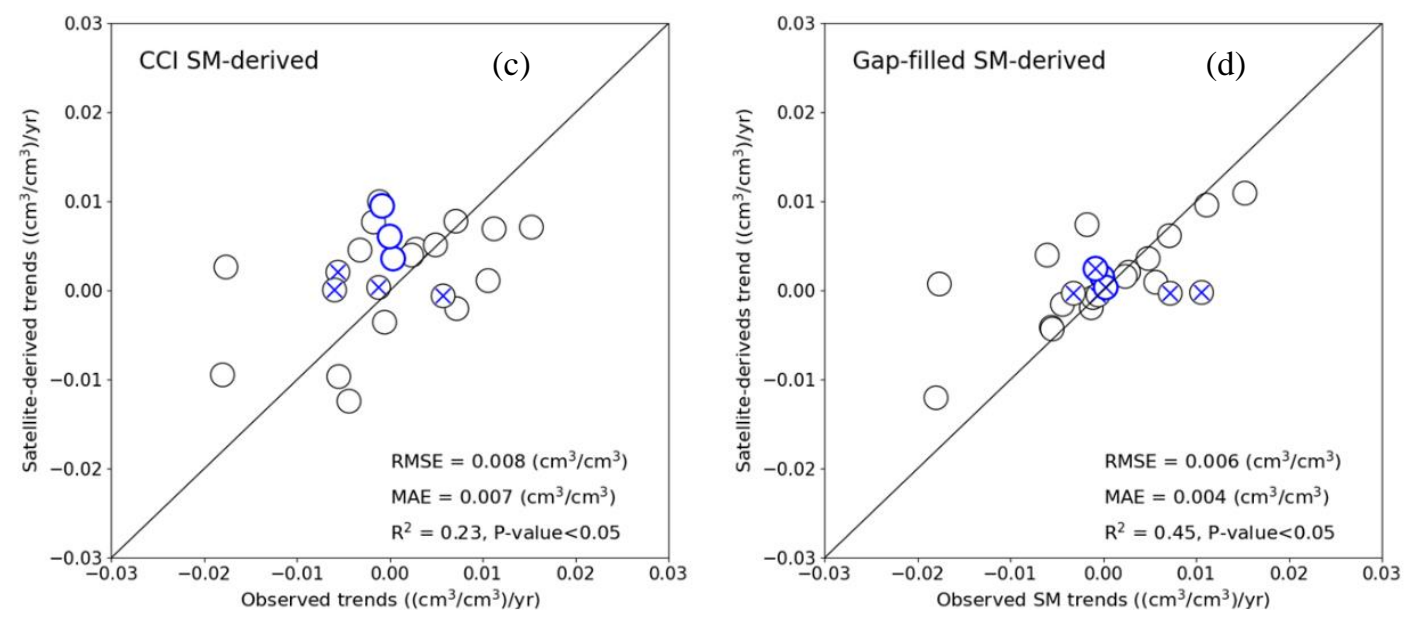

Figure 16: (a) shows the temporal patterns of raw CCI SM regarding different climate regions during 2005-2015, and (b) shows the temporal patterns of gap-filled CCI SM regarding different climate regions. The shaded area in (a) and (b) denotes \pm 1 standard error. (c) The scatter plot of 1-km CCI SM-derived trends against in situ measures during 2005-2014, and (d) the scatter plot of 1-km gap-filled SM-derived trends against in situ measures. The blue circle in (c) and (d) means the trends from in situ measures are under insignificance level, while the fork means the trends from satellite-derived SM are under insignificance level.

\section{Conclusions and future considerations}

The continuity of satellite-derived SM series is hampered by the data gap issues. This study thus provides a novel framework for reconstructing a spatially continuous daily SM dataset by integrating the ESA CCI SM and the related explanatory variables. To achieve this, one random forest method taking full account of both the spatial and temporal domains is designed. The explanatory variables filtered on the basis of a spatiotemporal window search strategy exhibit a substantial effect in driving RF regression, resulting in an efficacy improvement of $\sim 19 \%$. Meanwhile, model performance is enhanced by calibrating the derived residuals based on GWR and Gaussian filters. This improvement is manifested by the fact that the accuracies of gap-filling models are lowered by $\sim 9 \%$ when removing the residual calibration procedure.

Study presents the merit of identifying a sufficient number of explanatory variables from the integration of satellite observations and model-driven knowledge. The selected variables complementarily reproduce the SM dynamics in addition to capturing the spatial variations, which also implies that the nonlinear correlation between the SM and explanatory 
variables can be delineated on the spatiotemporal scale. Importance analysis illustrates that the accuracy of reconstructed SM is noticeably reduced when excluding each participating variable while keeping the rest variables. Specifically, in addition to conventional variables from optical remote sensing, the essential environment elements from model-driven knowledge are used to improve the performance of SM reconstruction. Earlier studies have suggested (Li et al., 2021a; Long et al., 2019) that the reanalysis dataset and land surface model product can provide spatiotemporally continuous records, indicating the great potential of simulating land surface parameters. Our study proposes to merge CCI SM time series with the reanalysis and land surface model dataset and applies to China. The reconstructed SM achieves satisfying accuracy, especially for areas with large swath gaps, underscoring the importance of spatial coverage and continuity of the environmental factors, and the multiple datasets should be involved in the gap-filled models. We further confirm this with one uncertainty analysis showing the feasibility of using alternative data sources of DTR and SM, which is essential at one long-term scale, especially considering the full coverage attribution of numerical model simulated products. Nevertheless, since the numerical model simulated models are generally sensitive to regional surface and climatic conditions, more representative model products such as CLDAS and regional numerical models can be considered in further work.

Machine learning is previously reported to be a powerful strategy for reconstructing contaminated values. Despite the effectiveness of RF models in situ SM databases, its applicability in reconstructing long-term satellite observational records especially across a large scale still deserves careful investigation. Here we manifest that the random forest, combined with the appropriate covariate exploiting both the spatial and temporal domains and the model-derived residual calibration module, can be a robust method in gap-filling the CCI SM database over China. The superiority of RF-based model in reconstructing SM is further proved by comparing it against the other four models. Despite this, more advanced machine learning strategies, such as deep neural networks (DNN) and long short-term memory (LSTM), are expected to enhance simulation accuracy. Specifically, the ensemble approaches mainly accounting for the scale biases among different gridded dataset are required. For example, one Bayesian modeling framework that can provide simulation standard error using uncertainty quantification is encouraged (Zhao et al., 2019a).

The variables forcing the proposed model are all from reliable data and long-term worldwide. Accordingly, the proposed method can be extended to generate a promising long-term gap-filled SM dataset. This is critical considering the spatiotemporally continuous SM is demanded for ecological and hydrological research. A promising result with a $\mathrm{R}^{2}$ of 0.72

605 is observed when applying our gap-filling approach to long-term SM data sets (2005-2015) in China. In particular, a more accurate trend is achieved relative to that of the original CCI SM when assessed with in situ measurements ( 0.45 versus 0.23 in terms of $\mathrm{R}^{2}$ ). Overall, our study may provide several insights for continuous monitoring of surface water dynamics and drought, and further promote the research of water resources management and climate change. 


\section{Code/Data availability}

610 All the datasets used in this study are open to the public. The National Aeronautics and Space Administration team provides the MODIS products, SRTM DEM data and GLDAS data freely download via the website https://earthdata.nasa.gov/. The ESA CCI soil moisture dataset and ERA-5 reanalysis datasets is collected from the European Centre for Medium-range Weather Forecasts (ECMWF) for providing (https://www.ecmwf.int/en/forecasts/datasets). The Brecht Martens, Diego Miralles and their team provides the GLEAM datasets (http://www.gleam.eu/). The China Watershed Allied Telemetry

615 Experimental Research (WATER) project, Chinese Ecosystem Research Network (CERN), and Maqu soil moisture monitoring network provides available in situ measurements at the website http://data.tpdc.ac.cn/en/. The Chinese regional ground meteorological dataset is collected from the National Tibetan Plateau Data Center (http://data.tpdc.ac.cn).

\section{Author contribution}

Kai Liu, Xueke Li, and Shudong Wang designed the theoretical formalism. Kai Liu performed the analytic calculations. Both Shudong Wang and Hongyan Zhang contributed to the final version of the paper.

\section{Competing interests}

The contact author has declared that neither they nor their co-authors have any competing interests.

\section{Acknowledgments}

This study was jointly supported by the Natural Science Foundation of China (42141007 and 41671362), and the Inner Mongolia Autonomous Region Science and Technology Achievement Transformation Special Fund Project (2021CG0045).

\section{References}

Almendra-Martín, L., Martínez-Fernández, J., Piles, M., and González-Zamora, Á.: Comparison of gap-filling techniques applied to the CCI soil moisture database in Southern Europe, Remote Sensing of Environment, 258, 112377, https://doi.org/10.1016/j.rse.2021.112377, 2021.

630 Amani, M., Salehi, B., Mahdavi, S., Masjedi, A., and Dehnavi, S.: Temperature-Vegetation-soil Moisture Dryness Index (TVMDI), Remote Sensing of Environment, 197, 1-14, https://doi.org/10.1016/j.rse.2017.05.026, 2017.

Balsamo, G., Albergel, C., Beljaars, A., Boussetta, S., Brun, E., Cloke, H., Dee, D., Dutra, E., Muñoz-Sabater, J., Pappenberger, F., de Rosnay, P., Stockdale, T., and Vitart, F.: ERA-Interim/Land: a global land surface reanalysis data set, Hydrol. Earth Syst. Sci., 19, 389-407, 10.5194/hess-19-389-2015, 2015. 
Belgiu, M. and Drăguţ, L.: Random forest in remote sensing: A review of applications and future directions, ISPRS Journal of Photogrammetry and Remote Sensing, 114, 24-31, https://doi.org/10.1016/j.isprsjprs.2016.01.011, 2016.

Chen, B., Xu, G., Coops, N. C., Ciais, P., Innes, J. L., Wang, G., Myneni, R. B., Wang, T., Krzyzanowski, J., Li, Q., Cao, L., and Liu, Y.: Changes in vegetation photosynthetic activity trends across the Asia-Pacific region over the last three decades, Remote Sensing of Environment, 144, 28-41, https://doi.org/10.1016/j.rse.2013.12.018, 2014.

640 Chen, Y. and Yuan, H.: Evaluation of nine sub-daily soil moisture model products over China using high-resolution in situ observations, Journal of Hydrology, 588, 125054, https://doi.org/10.1016/j.jhydrol.2020.125054, 2020.

Chen, Y., Yang, K., Qin, J., Zhao, L., Tang, W., and Han, M.: Evaluation of AMSR-E retrievals and GLDAS simulations against observations of a soil moisture network on the central Tibetan Plateau, Journal of Geophysical Research: Atmospheres, 118, 4466-4475, https://doi.org/10.1002/jgrd.50301, 2013.

645 Crow, W. T., Berg, A. A., Cosh, M. H., Loew, A., Mohanty, B. P., Panciera, R., de Rosnay, P., Ryu, D., and Walker, J. P.: Upscaling sparse ground-based soil moisture observations for the validation of coarse-resolution satellite soil moisture products, Reviews of Geophysics, 50, https://doi.org/10.1029/2011RG000372, 2012.

Cui, Y., Yang, X., Chen, X., Fan, W., Zeng, C., Xiong, W., and Hong, Y.: A two-step fusion framework for quality improvement of a remotely sensed soil moisture product: A case study for the ECV product over the Tibetan Plateau, Journal 650 of Hydrology, 587, 124993, https://doi.org/10.1016/j.jhydrol.2020.124993, 2020.

Cui, Y., Long, D., Hong, Y., Zeng, C., Zhou, J., Han, Z., Liu, R., and Wan, W.: Validation and reconstruction of FY3B/MWRI soil moisture using an artificial neural network based on reconstructed MODIS optical products over the Tibetan Plateau, Journal of Hydrology, 543, 242-254, https://doi.org/10.1016/j.jhydrol.2016.10.005, 2016.

Cui, Y., Zeng, C., Zhou, J., Xie, H., Wan, W., Hu, L., Xiong, W., Chen, X., Fan, W., and Hong, Y.: A spatio-temporal

655 continuous soil moisture dataset over the Tibet Plateau from 2002 to 2015, Scientific Data, 6, 247, 10.1038/s41597-0190228-x, 2019.

Dente, L., Vekerdy, Z., Wen, J., and Su, Z.: Maqu network for validation of satellite-derived soil moisture products, International Journal of Applied Earth Observation and Geoinformation, 17, 55-65, https://doi.org/10.1016/j.jag.2011.11.004, 2012.

660 Detto, M., Montaldo, N., Albertson, J. D., Mancini, M., and Katul, G.: Soil moisture and vegetation controls on evapotranspiration in a heterogeneous Mediterranean ecosystem on Sardinia, Italy, Water Resources Research, 42, https://doi.org/10.1029/2005WR004693, 2006.

Dorigo, W., Wagner, W., Albergel, C., Albrecht, F., Balsamo, G., Brocca, L., Chung, D., Ertl, M., Forkel, M., Gruber, A., Haas, E., Hamer, P. D., Hirschi, M., Ikonen, J., de Jeu, R., Kidd, R., Lahoz, W., Liu, Y. Y., Miralles, D., Mistelbauer, T., 665 Nicolai-Shaw, N., Parinussa, R., Pratola, C., Reimer, C., van der Schalie, R., Seneviratne, S. I., Smolander, T., and Lecomte, P.: ESA CCI Soil Moisture for improved Earth system understanding: State-of-the art and future directions, Remote Sensing of Environment, 203, 185-215, https://doi.org/10.1016/j.rse.2017.07.001, 2017. 
Dorigo, W. A., Gruber, A., De Jeu, R. A. M., Wagner, W., Stacke, T., Loew, A., Albergel, C., Brocca, L., Chung, D., Parinussa, R. M., and Kidd, R.: Evaluation of the ESA CCI soil moisture product using ground-based observations, Remote Sensing of Environment, 162, 380-395, https://doi.org/10.1016/j.rse.2014.07.023, 2015.

Dorigo, W. A., Wagner, W., Hohensinn, R., Hahn, S., Paulik, C., Xaver, A., Gruber, A., Drusch, M., Mecklenburg, S., van Oevelen, P., Robock, A., and Jackson, T.: The International Soil Moisture Network: a data hosting facility for global in situ soil moisture measurements, Hydrol. Earth Syst. Sci., 15, 1675-1698, 10.5194/hess-15-1675-2011, 2011.

Duan, Z. and Bastiaanssen, W. G. M.: First results from Version 7 TRMM 3B43 precipitation product in combination with a new downscaling-calibration procedure, Remote Sensing of Environment, 131, 1-13, https://doi.org/10.1016/j.rse.2012.12.002, 2013.

Entekhabi, D., Njoku, E. G., Neill, P. E. O., Kellogg, K. H., Crow, W. T., Edelstein, W. N., Entin, J. K., Goodman, S. D., Jackson, T. J., Johnson, J., Kimball, J., Piepmeier, J. R., Koster, R. D., Martin, N., McDonald, K. C., Moghaddam, M., Moran, S., Reichle, R., Shi, J. C., Spencer, M. W., Thurman, S. W., Tsang, L., and Zyl, J. V.: The Soil Moisture Active Passive (SMAP) Mission, Proceedings of the IEEE, 98, 704-716, 10.1109/JPROC.2010.2043918, 2010.

Ford, T. W. and Quiring, S. M.: Comparison and application of multiple methods for temporal interpolation of daily soil moisture, International Journal of Climatology, 34, 2604-2621, https://doi.org/10.1002/joc.3862, 2014.

Fu, G., Crosbie, R. S., Barron, O., Charles, S. P., Dawes, W., Shi, X., Van Niel, T., and Li, C.: Attributing variations of temporal and spatial groundwater recharge: A statistical analysis of climatic and non-climatic factors, Journal of Hydrology, 568, 816-834, https://doi.org/10.1016/j.jhydrol.2018.11.022, 2019.

Gruber, A., Scanlon, T., van der Schalie, R., Wagner, W., and Dorigo, W.: Evolution of the ESA CCI Soil Moisture climate data records and their underlying merging methodology, Earth Syst. Sci. Data, 11, 717-739, 10.5194/essd-11-717-2019, 2019.

Guan, X., Huang, J., Guo, N., Bi, J., and Wang, G.: Variability of soil moisture and its relationship with surface albedo and soil thermal parameters over the Loess Plateau, Advances in Atmospheric Sciences, 26, 692-700, 10.1007/s00376-009-8198$0,2009$.

Guisan, A., Weiss, S. B., and Weiss, A. D.: GLM versus CCA spatial modeling of plant species distribution, Plant Ecology, 143, 107-122, 10.1023/A:1009841519580, 1999.

Hu, L., Monaghan, A., Voogt, J. A., and Barlage, M.: A first satellite-based observational assessment of urban thermal anisotropy, Remote Sensing of Environment, 181, 111-121, https://doi.org/10.1016/j.rse.2016.03.043, 2016.

Huang, G., Li, X., Ma, M., Li, H., and Huang, C.: High resolution surface radiation products for studies of regional energy, hydrologic and ecological processes over Heihe river basin, northwest China, Agricultural and Forest Meteorology, 230-231, 67-78, https://doi.org/10.1016/j.agrformet.2016.04.007, 2016.

Jing, W., Zhang, P., and Zhao, X.: Reconstructing Monthly ECV Global Soil Moisture with an Improved Spatial Resolution, 
Karbalaye Ghorbanpour, A., Hessels, T., Moghim, S., and Afshar, A.: Comparison and assessment of spatial downscaling methods for enhancing the accuracy of satellite-based precipitation over Lake Urmia Basin, Journal of Hydrology, 596, 126055, https://doi.org/10.1016/j.jhydrol.2021.126055, 2021.

Kerr, Y. H., Waldteufel, P., Wigneron, J., Martinuzzi, J., Font, J., and Berger, M.: Soil moisture retrieval from space: the

Soil Moisture and Ocean Salinity (SMOS) mission, IEEE Transactions on Geoscience and Remote Sensing, 39, 1729-1735, 10.1109/36.942551, 2001.

Leng, P., Li, Z.-L., Duan, S.-B., Gao, M.-F., and Huo, H.-Y.: A practical approach for deriving all-weather soil moisture content using combined satellite and meteorological data, ISPRS Journal of Photogrammetry and Remote Sensing, 131, 4051, https://doi.org/10.1016/j.isprsjprs.2017.07.013, 2017.

710 Li, B., Liang, S., Liu, X., Ma, H., Chen, Y., Liang, T., and He, T.: Estimation of all-sky 1 km land surface temperature over the conterminous United States, Remote Sensing of Environment, 266, 112707, https://doi.org/10.1016/j.rse.2021.112707, 2021a.

Li, P., Zhang, L., Yu, G., Liu, C., Ren, X., He, H., Liu, M., Wang, H., Zhu, J., Ge, R., and Zeng, N.: Interactive effects of seasonal drought and nitrogen deposition on carbon fluxes in a subtropical evergreen coniferous forest in the East Asian monsoon region, Agricultural and Forest Meteorology, 263, 90-99, https://doi.org/10.1016/j.agrformet.2018.08.009, $2018 \mathrm{a}$.

Li, X., Liu, K., and Tian, J.: Variability, predictability, and uncertainty in global aerosols inferred from gap-filled satellite observations and an econometric modeling approach, Remote Sensing of Environment, 261, 112501, https://doi.org/10.1016/j.rse.2021.112501, 2021b.

Li, X., Zhang, C., Li, W., and Liu, K.: Evaluating the Use of DMSP/OLS Nighttime Light Imagery in Predicting PM2.5 720 Concentrations in the Northeastern United States, Remote Sensing, 9, 620, 2017.

Li, X., Li, X., Li, Z., Ma, M., Wang, J., Xiao, Q., Liu, Q., Che, T., Chen, E., Yan, G., Hu, Z., Zhang, L., Chu, R., Su, P., Liu, Q., Liu, S., Wang, J., Niu, Z., Chen, Y., Jin, R., Wang, W., Ran, Y., Xin, X., and Ren, H.: Watershed Allied Telemetry Experimental Research, Journal of Geophysical Research: Atmospheres, 114, https://doi.org/10.1029/2008JD011590, 2009.

Li, Y., Piao, S., Li, L. Z. X., Chen, A., Wang, X., Ciais, P., Huang, L., Lian, X., Peng, S., Zeng, Z., Wang, K., and Zhou, L.:

725 Divergent hydrological response to large-scale afforestation and vegetation greening in China, Science Advances, 4, eaar4182, doi:10.1126/sciadv.aar4182, 2018b.

Liu, K., Li, X., and Long, X.: Trends in groundwater changes driven by precipitation and anthropogenic activities on the southeast side of the Hu Line, Environmental Research Letters, 16, 094032, 10.1088/1748-9326/ac1ed8, 2021a.

Liu, K., Li, X., and Wang, S.: Characterizing the spatiotemporal response of runoff to impervious surface dynamics across 730 three highly urbanized cities in southern China from 2000 to 2017, International Journal of Applied Earth Observation and Geoinformation, 100, 102331, https://doi.org/10.1016/j.jag.2021.102331, 2021b.

Liu, K., Su, H., Li, X., and Chen, S.: Development of a 250-m Downscaled Land Surface Temperature Data Set and Its Application to Improving Remotely Sensed Evapotranspiration Over Large Landscapes in Northern China, IEEE Transactions on Geoscience and Remote Sensing, 1-12, 10.1109/TGRS.2020.3037168, 2020a. 
Liu, K., Wang, S., Li, X., and Wu, T.: Spatially Disaggregating Satellite Land Surface Temperature With a Nonlinear Model Across Agricultural Areas, Journal of Geophysical Research: Biogeosciences, 124, 3232-3251, https://doi.org/10.1029/2019JG005227, 2019.

Liu, Y., Yao, L., Jing, W., Di, L., Yang, J., and Li, Y.: Comparison of two satellite-based soil moisture reconstruction algorithms: A case study in the state of Oklahoma, USA, Journal of Hydrology, 590, 125406, https://doi.org/10.1016/j.jhydrol.2020.125406, 2020b.

Llamas, R. M., Guevara, M., Rorabaugh, D., Taufer, M., and Vargas, R.: Spatial Gap-Filling of ESA CCI Satellite-Derived Soil Moisture Based on Geostatistical Techniques and Multiple Regression, Remote Sensing, 12, 665, 2020.

Long, D., Bai, L., Yan, L., Zhang, C., Yang, W., Lei, H., Quan, J., Meng, X., and Shi, C.: Generation of spatially complete and daily continuous surface soil moisture of high spatial resolution, Remote Sensing of Environment, 233, 111364, https://doi.org/10.1016/j.rse.2019.111364, 2019.

Long, D., Yan, L., Bai, L., Zhang, C., Li, X., Lei, H., Yang, H., Tian, F., Zeng, C., Meng, X., and Shi, C.: Generation of MODIS-like land surface temperatures under all-weather conditions based on a data fusion approach, Remote Sensing of Environment, 246, 111863, https://doi.org/10.1016/j.rse.2020.111863, 2020.

Mahto, S. S. and Mishra, V.: Does ERA-5 Outperform Other Reanalysis Products for Hydrologic Applications in India?, 750 Journal of Geophysical Research: Atmospheres, 124, 9423-9441, https://doi.org/10.1029/2019JD031155, 2019.

Mao, H., Kathuria, D., Duffield, N., and Mohanty, B. P.: Gap Filling of High-Resolution Soil Moisture for SMAP/Sentinel1: A Two-Layer Machine Learning-Based Framework, Water Resources Research, 55, 6986-7009, https://doi.org/10.1029/2019WR024902, 2019.

Meng, X., Mao, K., Meng, F., Shi, J., Zeng, J., Shen, X., Cui, Y., Jiang, L., and Guo, Z.: A fine-resolution soil moisture dataset for China in 2002-2018, Earth Syst. Sci. Data, 13, 3239-3261, 10.5194/essd-13-3239-2021, 2021.

Merlin, O., Jacob, F., Wigneron, J., Walker, J., and Chehbouni, G.: Multidimensional Disaggregation of Land Surface Temperature Using High-Resolution Red, Near-Infrared, Shortwave-Infrared, and Microwave-L Bands, IEEE Transactions on Geoscience and Remote Sensing, 50, 1864-1880, 10.1109/TGRS.2011.2169802, 2012.

Miralles, D. G., Holmes, T. R. H., De Jeu, R. A. M., Gash, J. H., Meesters, A. G. C. A., and Dolman, A. J.: Global landsurface evaporation estimated from satellite-based observations, Hydrol. Earth Syst. Sci., 15, 453-469, 10.5194/hess-15-4532011, 2011.

Molero, B., Merlin, O., Malbéteau, Y., Al Bitar, A., Cabot, F., Stefan, V., Kerr, Y., Bacon, S., Cosh, M. H., Bindlish, R., and Jackson, T. J.: SMOS disaggregated soil moisture product at $1 \mathrm{~km}$ resolution: Processor overview and first validation results, Remote Sensing of Environment, 180, 361-376, https://doi.org/10.1016/j.rse.2016.02.045, 2016.

Otkin, J. A., Anderson, M. C., Hain, C., Svoboda, M., Johnson, D., Mueller, R., Tadesse, T., Wardlow, B., and Brown, J.: Assessing the evolution of soil moisture and vegetation conditions during the 2012 United States flash drought, Agricultural and Forest Meteorology, 218-219, 230-242, https://doi.org/10.1016/j.agrformet.2015.12.065, 2016. 
Paloscia, S., Macelloni, G., Santi, E., and Koike, T.: A multifrequency algorithm for the retrieval of soil moisture on a large scale using microwave data from SMMR and SSM/I satellites, IEEE Transactions on Geoscience and Remote Sensing, 39, 1655-1661, 10.1109/36.942543, 2001.

Piles, M., Petropoulos, G. P., Sánchez, N., González-Zamora, Á., and Ireland, G.: Towards improved spatio-temporal resolution soil moisture retrievals from the synergy of SMOS and MSG SEVIRI spaceborne observations, Remote Sensing of Environment, 180, 403-417, https://doi.org/10.1016/j.rse.2016.02.048, 2016.

Prihodko, L., Denning, A. S., Hanan, N. P., Baker, I., and Davis, K.: Sensitivity, uncertainty and time dependence of parameters in a complex land surface model, Agricultural and Forest Meteorology, 148, 268-287, https://doi.org/10.1016/j.agrformet.2007.08.006, 2008.

Ramoelo, A., Cho, M. A., Mathieu, R., Madonsela, S., van de Kerchove, R., Kaszta, Z., and Wolff, E.: Monitoring grass nutrients and biomass as indicators of rangeland quality and quantity using random forest modelling and WorldView-2 data, International Journal of Applied Earth Observation and Geoinformation, 43, 43-54, https://doi.org/10.1016/j.jag.2014.12.010, 2015.

Reichle, R. H., Koster, R. D., De Lannoy, G. J. M., Forman, B. A., Liu, Q., Mahanama, S. P. P., and Touré, A.: Assessment and Enhancement of MERRA Land Surface Hydrology Estimates, Journal of Climate, 24, 6322-6338, 10.1175/jcli-d-1005033.1, 2011.

Reichstein, M., Camps-Valls, G., Stevens, B., Jung, M., Denzler, J., Carvalhais, N., and Prabhat: Deep learning and process understanding for data-driven Earth system science, Nature, 566, 195-204, 10.1038/s41586-019-0912-1, 2019.

Schaake, J. C., Duan, Q., Koren, V., Mitchell, K. E., Houser, P. R., Wood, E. F., Robock, A., Lettenmaier, D. P., Lohmann, D., Cosgrove, B., Sheffield, J., Luo, L., Higgins, R. W., Pinker, R. T., and Tarpley, J. D.: An intercomparison of soil moisture fields in the North American Land Data Assimilation System (NLDAS), Journal of Geophysical Research: Atmospheres, 109, https://doi.org/10.1029/2002JD003309, 2004.

Shahriari, B., Swersky, K., Wang, Z., Adams, R. P., and Freitas, N. d.: Taking the Human Out of the Loop: A Review of Bayesian Optimization, Proceedings of the IEEE, 104, 148-175, 10.1109/JPROC.2015.2494218, 2016.

Sismanidis, P., Bechtel, B., Keramitsoglou, I., Göttsche, F., and Kiranoudis, C. T.: Satellite-derived quantification of the diurnal and annual dynamics of land surface temperature, Remote Sensing of Environment, 265, 112642, https://doi.org/10.1016/j.rse.2021.112642, 2021.

Song, P., Zhang, Y., and Tian, J.: Improving Surface Soil Moisture Estimates in Humid Regions by an Enhanced Remote Sensing Technique, Geophysical Research Letters, 48, e2020GL091459, https://doi.org/10.1029/2020GL091459, 2021.

Stroud, J. R., Müller, P., and Sansó, B.: Dynamic models for spatiotemporal data, Journal of the Royal Statistical Society: Series B (Statistical Methodology), 63, 673-689, https://doi.org/10.1111/1467-9868.00305, 2001.

Su, Z., de Rosnay, P., Wen, J., Wang, L., and Zeng, Y.: Evaluation of ECMWF's soil moisture analyses using observations 800 on the Tibetan Plateau, Journal of Geophysical Research: Atmospheres, 118, 5304-5318, https://doi.org/10.1002/jgrd.50468, 2013. 
Svetnik, V., Liaw, A., Tong, C., Culberson, J. C., Sheridan, R. P., and Feuston, B. P.: Random Forest: A Classification and Regression Tool for Compound Classification and QSAR Modeling, Journal of Chemical Information and Computer Sciences, 43, 1947-1958, 10.1021/ci034160g, 2003.

805 Uebbing, B., Forootan, E., Braakmann-Folgmann, A., and Kusche, J.: Inverting surface soil moisture information from satellite altimetry over arid and semi-arid regions, Remote Sensing of Environment, 196, 205-223, https://doi.org/10.1016/j.rse.2017.05.004, 2017.

van Zyl, J. J.: The Shuttle Radar Topography Mission (SRTM): a breakthrough in remote sensing of topography, Acta Astronautica, 48, 559-565, https://doi.org/10.1016/S0094-5765(01)00020-0, 2001.

810 Wanders, N., Karssenberg, D., de Roo, A., de Jong, S. M., and Bierkens, M. F. P.: The suitability of remotely sensed soil moisture for improving operational flood forecasting, Hydrol. Earth Syst. Sci., 18, 2343-2357, 10.5194/hess-18-2343-2014, 2014.

Wang, A., Lettenmaier, D. P., and Sheffield, J.: Soil Moisture Drought in China, 1950-2006, Journal of Climate, 24, 32573271, 10.1175/2011jcli3733.1, 2011.

815 Wang, C., Xie, Q., Gu, X., Yu, T., Meng, Q., Zhou, X., Han, L., and Zhan, Y.: Soil moisture estimation using Bayesian Maximum Entropy algorithm from FY3-B, MODIS and ASTER GDEM remote-sensing data in a maize region of HeBei province, China, International Journal of Remote Sensing, 41, 7018-7041, 10.1080/01431161.2020.1752953, 2020.

Wang, S., Mo, X., Liu, S., Lin, Z., and Hu, S.: Validation and trend analysis of ECV soil moisture data on cropland in North China Plain during 1981-2010, International Journal of Applied Earth Observation and Geoinformation, 48, 110-121, https://doi.org/10.1016/j.jag.2015.10.010, 2016.

Wei, F., Wang, S., Fu, B., Brandt, M., Pan, N., Wang, C., and Fensholt, R.: Nonlinear dynamics of fires in Africa over recent decades controlled by precipitation, Global Change Biology, 26, 4495-4505, https://doi.org/10.1111/gcb.15190, 2020.

Wei, Z., Meng, Y., Zhang, W., Peng, J., and Meng, L.: Downscaling SMAP soil moisture estimation with gradient boosting decision tree regression over the Tibetan Plateau, Remote Sensing of Environment, 225, 30-44, https://doi.org/10.1016/j.rse.2019.02.022, 2019.

Yao, X., Fu, B., Lü, Y., Sun, F., Wang, S., and Liu, M.: Comparison of Four Spatial Interpolation Methods for Estimating Soil Moisture in a Complex Terrain Catchment, PLOS ONE, 8, e54660, 10.1371/journal.pone.0054660, 2013.

Yao, Y., Liang, S., Cao, B., Liu, S., Yu, G., Jia, K., Zhang, X., Zhang, Y., Chen, J., and Fisher, J. B.: Satellite Detection of Water Stress Effects on Terrestrial Latent Heat Flux With MODIS Shortwave Infrared Reflectance Data, Journal of 830 Geophysical Research: Atmospheres, 123, 11,410-411,430, https://doi.org/10.1029/2018JD029011, 2018.

Yu, G.-R., Wen, X.-F., Sun, X.-M., Tanner, B. D., Lee, X., and Chen, J.-Y.: Overview of ChinaFLUX and evaluation of its eddy covariance measurement, Agricultural and Forest Meteorology, 137, 125-137, https://doi.org/10.1016/j.agrformet.2006.02.011, 2006. 
Zhang, C., Long, D., Zhang, Y., Anderson, M. C., Kustas, W. P., and Yang, Y.: A decadal (2008-2017) daily evapotranspiration data set of $1 \mathrm{~km}$ spatial resolution and spatial completeness across the North China Plain using TSEB and data fusion, Remote Sensing of Environment, 262, 112519, https://doi.org/10.1016/j.rse.2021.112519, 2021a.

Zhang, L., Liu, Y., Ren, L., Teuling, A. J., Zhang, X., Jiang, S., Yang, X., Wei, L., Zhong, F., and Zheng, L.: Reconstruction of ESA CCI satellite-derived soil moisture using an artificial neural network technology, Science of The Total Environment, 782, 146602, https://doi.org/10.1016/j.scitotenv.2021.146602, 2021 b.

840 Zhang, Q., Yuan, Q., Li, J., Wang, Y., Sun, F., and Zhang, L.: Generating seamless global daily AMSR2 soil moisture (SGD-SM) long-term products for the years 2013-2019, Earth Syst. Sci. Data, 13, 1385-1401, 10.5194/essd-13-1385-2021, $2021 \mathrm{c}$.

Zhang, X., Zhou, J., Liang, S., and Wang, D.: A practical reanalysis data and thermal infrared remote sensing data merging (RTM) method for reconstruction of a 1-km all-weather land surface temperature, Remote Sensing of Environment, 260,

845 112437, https://doi.org/10.1016/j.rse.2021.112437, 2021d.

Zhang, X., Chen, B., Zhao, H., Fan, H., and Zhu, D.: Soil Moisture Retrieval over a Semiarid Area by Means of PCA Dimensionality Reduction, Canadian Journal of Remote Sensing, 42, 136-144, 10.1080/07038992.2016.1175928, 2016.

Zhao, K., Wulder, M. A., Hu, T., Bright, R., Wu, Q., Qin, H., Li, Y., Toman, E., Mallick, B., Zhang, X., and Brown, M.: Detecting change-point, trend, and seasonality in satellite time series data to track abrupt changes and nonlinear dynamics: A

850 Bayesian ensemble algorithm, Remote Sensing of Environment, 232, 111181, https://doi.org/10.1016/j.rse.2019.04.034, 2019a.

Zhao, W., Duan, S.-B., Li, A., and Yin, G.: A practical method for reducing terrain effect on land surface temperature using random forest regression, Remote Sensing of Environment, 221, 635-649, https://doi.org/10.1016/j.rse.2018.12.008, 2019b.

Zhao, W., Sánchez, N., Lu, H., and Li, A.: A spatial downscaling approach for the SMAP passive surface soil moisture product using random forest regression, Journal of Hydrology, 563, 1009-1024, https://doi.org/10.1016/j.jhydrol.2018.06.081, 2018.

Zhu, L., Sun, O. J., Sang, W., Li, Z., and Ma, K.: Predicting the spatial distribution of an invasive plant species (Eupatorium adenophorum) in China, Landscape Ecology, 22, 1143-1154, 10.1007/s10980-007-9096-4, 2007.

Zhu, X., Liu, D., and Chen, J.: A new geostatistical approach for filling gaps in Landsat ETM+ SLC-off images, Remote 